\title{
Epithelial requirement for in vitro proliferation and xenograft growth and metastasis of MDA-MB-468 human breast cancer cells: oncogenic rather than tumor- suppressive role of E-cadherin
}

\author{
H. J. Hugo ${ }^{1,2,3,4^{*+}}$, N. P. A. D. Gunasinghe ${ }^{1 \dagger}$, B. G. Hollier ${ }^{8,9}$, T. Tanaka ${ }^{4}$, T. Blick ${ }^{1,2,3,4}$, A. Toh ${ }^{2,3,4}$, P. Hill ${ }^{6}$, C. Gilles ${ }^{7}$, \\ M. Waltham ${ }^{1,2,3}$ and E. W. Thompson ${ }^{1,2,3,4,5}$
}

\begin{abstract}
Background: Epithelial-to-mesenchymal transition (EMT) is associated with downregulated E-cadherin and frequently with decreased proliferation. Proliferation may be restored in secondary metastases by mesenchymal-to-epithelial transition (MET). We tested whether E-cadherin maintains epithelial proliferation in MDA-MB-468 breast cancer cells, facilitating metastatic colonization in severe combined immunodeficiency (SCID) mice.

Methods: EMT/MET markers were assessed in xenograft tumors by immunohistochemistry. Stable E-cadherin manipulation was effected by transfection and verified by Western blotting, immunocytochemistry, and quantitative polymerase chain reaction ( $\mathrm{PPCR}$ ). Effects of E-cadherin manipulation on proliferation and chemomigration were assessed in vitro by performing sulforhodamine B assays and Transwell assays, respectively. Invasion was assessed by Matrigel outgrowth; growth in vivo was assessed in SCID mice; and EMT status was assessed by qPCR. Hypoxic response of E-cadherin knockdown cell lines was assessed by GPCR after hypoxic culture. Repeated measures analysis of variance (ANOVA), one- and two-way ANOVA with posttests, and paired Student's $t$ tests were performed to determine significance $(p<0.05)$.

(Continued on next page)
\end{abstract}

\footnotetext{
*Correspondence: honor.hugo@qut.edu.au

${ }^{\dagger}$ Equal contributors

${ }^{1}$ Invasion and Metastasis Unit, St. Vincent's Institute, Melbourne, VIC, Australia

${ }^{2}$ Institute of Health and Biomedical Innovation, Queensland University of

Technology, Brisbane, QLD, Australia

Full list of author information is available at the end of the article
} 
(Continued from previous page)

Results: EMT occurred at the necrotic interface of MDA-MB-468 xenografts in regions of hypoxia. Extratumoral deposits (vascular and lymphatic inclusions, local and axillary nodes, and lung metastases) strongly expressed E-cadherin. MDAMB-468 cells overexpressing E-cadherin were more proliferative and less migratory in vitro, whereas E-cadherin knockdown (short hairpin $\mathrm{CDH} 1$ [shCDH1]) cells were more migratory and invasive, less proliferative, and took longer to form tumors. shCDH1-MDA-MB-468 xenografts did not contain the hypoxia-induced necrotic areas observed in wild-type (WT) and shSCR-MDA-MB-468 tumors, but they did not exhibit an impaired hypoxic response in vitro. Although vimentin expression was not stimulated by E-cadherin knockdown in 2D or 3D cultures, xenografts of these cells were globally vimentin-positive rather than exhibiting regional EMT, and they expressed higher SNA1 than their in vitro counterparts. E-cadherin suppression caused a trend toward reduced lung metastasis, whereas E-cadherin overexpression resulted in the reverse trend, consistent with the increased proliferation rate and predominantly epithelial phenotype of MDA-MB-468 cells outside the primary xenograft. This was also originally observed in WT xenografts. Furthermore, we found that patients with breast cancer that expressed E-cadherin were more likely to have metastases.

Conclusions: E-cadherin expression promotes growth of primary breast tumors and conceivably the formation of metastases, supporting a role for MET in metastasis. E-cadherin needs to be reevaluated as a tumor suppressor.

Keywords: Breast cancer, E-cadherin, Epithelial-to-mesenchymal transition, Epithelial-mesenchymal plasticity, Proliferation, Metastasis

\section{Background}

In 2016 alone, 3073 people died as a result of breast cancer in Australia [1], with essentially all breast cancer deaths being due to metastasis [2, 3]. Accumulating evidence suggests that epithelial-mesenchymal plasticity (EMP), which is critical for the formation of new tissues during embryonic development, also facilitates metastasis from carcinomas, including breast cancer $[4,5]$. In parallel to its role in normal mammary gland development [6-11], EMP in the mesenchymal direction (epithelial-to-mesenchymal transition [EMT]) is responsible for converting a fraction of noninvasive tumor cells from a carcinoma into stemlike cells with the ability to resist therapies, migrate, invade, intravasate, and survive in the systemic circulation $[12,13]$. The reverse, mesenchymal-to-epithelial transition (MET), is thought to allow cells the cohesiveness to colonize new sites (reviewed in [4, 14-18]).

E-cadherin is a $\mathrm{Ca}^{2+}$-dependent transmembrane glycoprotein present in the epithelial cell membrane, maintaining intercellular adhesion through the formation of adherens junctions [19, 20]. E-cadherin plays a pivotal role in embryonic morphogenesis, mainly through governing early cellular differentiation pathways $[21,22]$. Functional loss or downregulation of E-cadherin from epithelial cells is considered a hallmark of EMT [23, 24]. The first transcriptional suppressor of E-cadherin and inducer of EMT to be identified was the zinc finger transcription factor Snail family transcriptional repressor 1 (SNAI1) [24, 25]. Since then, other E-cadherin suppressors and EMT inducers, such as Snail family transcriptional repressor 2 (SNAI2, Slug), zinc finger E-box-binding homeobox 1 (ZEB1)/TCF8, ZEB2 (SIP-1), Goosecoid, Twist-1, and Forkhead box protein C2 (FOXC2), have emerged [26-
32]. All of these transcription regulators downregulate Ecadherin expression, potentially inducing EMT [33]. Given the striking similarities between cell translocation during embryonic morphogenesis and cancer metastasis $[34,35]$, E-cadherin has emerged as an important candidate regulator of the metastatic process in cancers of epithelial origin [36, 37].

Although EMT is a major mechanism contributing to tumor progression, unchecked cellular proliferation is the driver of tumor growth. Accumulating evidence suggests that EMT and cellular proliferation are inversely associated and that EMT attenuates cell proliferation in some [38, 39] but not all $[40,41]$ systems. Researchers in an early study on well-differentiated colorectal adenocarcinomas with lymph node (LN) metastasis reported loss of the proliferative marker Ki-67 in the cells along the invasive front in de-differentiated primary and secondary tumors, in contrast to the presence of high $\mathrm{Ki}-67$ at the tumor center [42]. They observed diminished membranous E-cadherin and nuclear localized $\beta$-catenin in the Ki-67-negative cells at the invasive front, indicating attenuated proliferation in cells that have undergone EMT. This is reflected by the more recent finding that breast cancer stem cells located at the invasive front are primarily quiescent, whereas those in a more central location within the tumor are proliferative and retain the ability to transition between these states [43]. In turn, the antiproliferative drug cisplatin has been shown to induce EMT [44]. We have shown in breast cancer cells that suppression of proliferation by EMT is mediated at least in part through $Z E B 1$ repression of $M Y B$, a gene important in driving proliferation of estrogen receptor (ER)-positive primary breast cancers [38]. 
MET is also critical in the developmental formation of new tissues as occurs in nephrogenesis [45], and it fuels the formation of metastatic tumors at the secondary site $[4,14,18,46-50]$. Chao et al. [46] reported reexpression of E-cadherin in distant metastases arising in organs such as the liver, brain, and lung from primary breast tumors that were E-cadherin-low or E-cadherin-negative, and they suggested that the reexpression of E-cadherin in metastases was mediated by E-cadherin promoter demethylation influenced by the microenvironment of the metastatic site. Several other studies support the reexpression of E-cadherin at secondary sites [51-53]. This reexpression may reactivate cellular proliferation within the cells that emerge from the circulation at the secondary site, allowing them to form bulky metastases within the targeted niche organ, as reviewed elsewhere $[14,54,55]$.

Although xenografts of MDA-MB-468 human breast cancer cells have been well described [56-58], relatively few studies have explored metastasis and EMP [59-61]. In the present study, we examined further the relationships between EMP status, proliferation, and metastasis through manipulation of E-cadherin in these cells.

\section{Methods}

\section{Cell line and culture conditions}

The MDA-MB-468 breast cancer cell line used in this study was originally obtained from the American Type Culture Collection (Manassas, VA, USA) by the Georgetown Lombardi Comprehensive Cancer Center (Washington, DC, USA) [62]. Cell cultures were routinely maintained in DMEM (Sigma-Aldrich, St. Louis, MO, USA) containing glucose $(4500 \mathrm{mg} / \mathrm{L})$, L-glutamine, and sodium pyruvate $(110 \mathrm{mg} / \mathrm{L})$ and supplemented with 10\% FBS (SAFC Biosciences, Castle Hill, Australia). Cultures were maintained in antibiotic-free growth medium at $37{ }^{\circ} \mathrm{C}$ in a humidified incubator with $\mathrm{O}_{2}$ and $\mathrm{CO}_{2}$ levels set at $21 \%$ and $5 \%$, respectively. For induction of hypoxia (HPX) in culture, the cells were passaged in DMEM supplemented with $10 \%$ FBS and incubated at $37^{\circ} \mathrm{C}$ on an $\mathrm{InvivO}_{2} 400$ workstation (Ruskinn Technology Ltd, Bridgend, UK) at $1 \% \mathrm{O}_{2}$ and $5 \% \mathrm{CO}_{2}$, and the cells were harvested at $48 \mathrm{~h}$.

\section{Immunocytochemistry}

MDA-MB-468 cells were plated in 96-well Terasaki plates $\left(\mathrm{Nunc}^{\mathrm{TM}}\right.$; Thermo Fisher Scientific, Roskilde, Denmark), and immunofluorescence was performed as previously described [38]. A volume of $12 \mu \mathrm{l}$ per Terasaki well was used.

\section{Immunohistochemistry}

Formalin-fixed, paraffin-embedded tissues were sectioned onto microscopic slides (SuperFrost ${ }^{\circledR}$ Plus; Menzel-Gläser, Braunschweig, Germany). Slides were then incubated in a humidified chamber with the primary antibody (antibodies used are listed in Table 2) and diluted in blocking buffer (PBS with $0.1 \%$ bovine serum albumin [BSA]) for $1 \mathrm{~h}$ at room temperature or at $4{ }^{\circ} \mathrm{C}$ overnight. The slides were next incubated with a biotinylated secondary antibody (raised against the immunoglobulin G [IgG] of the primary IgG species) for $1 \mathrm{~h}$ at room temperature, then incubated with HRP-conjugated streptavidin-biotin complex (Dako, Glostrup, Denmark) for $1 \mathrm{~h}$ at room temperature and stained with freshly prepared 3,3'-diaminobenzidine (DAB; Sigma-Aldrich). Slides were counterstained with hematoxylin for 5 minutes, mounted in dibutylphthalate polystyrene xylene (DPX), and coverslipped. The double immunohistochemistry (IHC) was performed using the BenchMark ${ }^{\circ}$ ULTRA automated slide stainer (Ventana Medical Systems, Inc., Tucson, AZ, USA) in the Department of Pathology, St. Vincent's Hospital, Melbourne, Australia. The chromogens used were ultraView ${ }^{\circ}$ Universal Alkaline Phosphatase Fast Red (red color, vimentin) and ultraView ${ }^{\circ}$ Universal DAB (brown color, E-cadherin) (both from Ventana Medical Systems, Inc.).

\section{Obtaining red-channel images}

The color deconvolution plugin in ImageJ software (version 1.51j8; public domain program created by Wayne Rasband, National Institutes of Health, Bethesda, MD, USA) was used, set for Fast Red DAB, to obtain the red channel images in the E-cadherin/vimentin dual-stained images.

\section{Sulforhodamine B cell proliferation assay}

The sulforhodamine B (SRB) colorimetric assay (SigmaAldrich) measures the amount of protein content, which is proportional to the number of cells [63]. The assays were performed in 96-well tissue culture plates containing $0.1 \mathrm{ml}$ of culture medium per well and between 2500 and 20,000 cells per well. A series of plates were prepared with a desired number of cells per well and incubated at $37{ }^{\circ} \mathrm{C}$ in an incubator with $\mathrm{O}_{2}$ and $\mathrm{CO}_{2}$ set at $21 \%$ and $0.5 \%$, respectively. The day of cell seeding was considered as day -2 . One day after cell seeding (day -1 ), the normal culture medium was replaced with serum-free medium, followed by incubation for $24 \mathrm{~h}$. Plates were fixed in 50\% trichloroacetic acid (TCA), then $25 \mu \mathrm{l}$ of prechilled $\left(4{ }^{\circ} \mathrm{C}\right) 50 \%$ TCA was gently added to the growth medium in each well to give a final concentration of $10 \%$ TCA. The plates were then incubated at $4{ }^{\circ} \mathrm{C}$ for $1 \mathrm{~h}$, followed by gentle washing with tap water. Washes were repeated five times for complete removal of TCA and growth medium and then air-dried overnight and stored at room temperature. At the end of the experiment, once all the plates had been TCA-fixed and air-dried, they were collectively stained for 30 minutes by adding $100 \mu \mathrm{l}$ of freshly prepared $0.4 \%$ SRB (wt/vol) in $1 \%$ acetic acid per well. The plates were then washed 
five times with $1 \%$ acetic acid to completely remove protein-unbound stain. Plates were air-dried overnight at room temperature. SRB dye-bound protein appears bright pink in color. This was solubilized by adding $100 \mu \mathrm{l}$ of $10 \mathrm{mM}$ Tris base (pH 10.5) and incubating for 20-30 minutes on a gyratory shaker at room temperature. The optical density (OD) of absorbance at 540-nm wavelength was then measured in a microplate reader (POLARstar OPTIMA; BMG LABTECH, Ortenberg, Germany). The average of the OD values measured in the PBS-containing outer wells, which was generally about 0.04 , was considered as the background OD. The results were analyzed using Prism version 5 software (GraphPad Software, La Jolla, CA, USA).

\section{Creation of modified cell lines}

E-cadherin was exogenously expressed in MDA-MB-468 cells, referred to as 468-CDH1, by transfecting the cells with the plasmid hECD-pcDNA3 [64] using Lipofectami$\mathrm{ne}^{\mathrm{TM}} 2000$ reagent (Invitrogen, Carlsbad, CA, USA) according to the manufacturer's instructions. The cells were maintained in $600 \mu \mathrm{g} / \mathrm{ml}$ of G418 (geneticin; Invitrogen) in growth medium for 6-8 weeks to establish a stable, pooled cell line. Short hairpin RNA (shRNA)-expressing MDA-MB-468 cell pools, referred to as 468-shCDH1-A, $-B$, $-C$, or $-D$, were generated using the Lenti-X HTX packaging system (Clontech Laboratories, Mountain View, CA, USA). shRNA sequences (Table 1), along with a nonsilencing shRNA microRNA (miR) lentiviral control vector containing a scrambled sequence with no homology to any known mammalian genes (Open Biosystems, Lafayette, CO, USA), were encoded within a green fluorescent protein (GFP)-expressing lentiviral vector (pGIPZ; Open Biosystems). Successfully transduced cells were selected by cell sorting for GFP; thus, a transduced pool rather than individual clones was used in these studies.

\section{Western blotting and quantitative real-time polymerase chain reaction experiments}

These techniques were performed as previously described [38] to determine the degree of E-cadherin overexpression, depletion, or knockdown in the various modified cell lines. Antibodies used are detailed in Table 2. Quantitative realtime polymerase chain reaction (RT-qPCR) experiments were performed using gene-specific primers designed specially to detect either the exogenously expressed E-

Table 1 Short hairpin RNA used in this study

\begin{tabular}{lll}
\hline Cell line & Clone ID & Sequence \\
\hline 468-shCDH1-A & V2LHS_14834 & CTGTTGGTGTCTTTATTAT \\
468-shCDH1-B & V2LHS_14838 & GTCGTAATCACCACACTGA \\
468-shCDH1-C & V2LHS_14837 & CCAACTGGCTGGAGATTAA \\
468-shCDH1-D & V2LHS_243170 & GAGAGAGTTTCCCTACGTA \\
\hline
\end{tabular}

cadherin or the targeted sequences in shRNA-infected cells. Primer sequences are detailed in Table 3.

\section{Transwell chemotaxis migration assay}

The Transwell migration assay was performed using 24well Transwell $^{\circ}$ permeable inserts containing polycarbonate membranes with $6.5-\mathrm{mm}$ diameter, $8-\mu \mathrm{m}$ pore size, and $0.3-\mathrm{cm}^{3}$ bottom area (catalogue number 3422 ; Corning Life Sciences, Corning, NY, USA). MDA-MB468 cells were resuspended at $1 \times 10^{6}$ live cells $/ \mathrm{ml}$ in FBS-free DMEM supplemented with 0.1\% BSA. While the cell suspensions were prepared, $600 \mu \mathrm{l}$ of the chemoattractant (DMEM supplemented with 10\% FBS and $0.1 \%$ BSA) was dispensed into each well of the 24-well Transwell plates and warmed to $37{ }^{\circ} \mathrm{C}$. The Transwell inserts were placed in the bottom wells containing prewarmed chemoattractant, and $1 \times 10^{5}$ cells $(100 \mu \mathrm{l}$ from the cell suspension) were applied to each well. The Transwell plates were then incubated at $37{ }^{\circ} \mathrm{C}$ for $4.5 \mathrm{~h}$, after which the growth medium in the inserts was removed and the membranes were washed twice in PBS. The membranes were then fixed in methanol for $1 \mathrm{mi}$ nute and stained with Diff-Quik (Siemens, Bayswater, Australia) for 1 minute with eosin followed by 1 minute with buffered thiazole and washed with several changes of water to completely remove excess stain. The nonmigrated cells on the top side of the membranes were gently wiped off using wet cotton swabs. The membranes were left to air-dry overnight, carefully peeled off from the inserts, and placed onto microscopic slides with the migrated cells facing down, mounted in DPX mounting medium, and coverslipped. The number of migrated cells in five random high-power fields per membrane was counted using ImageJ software.

\section{Matrigel outgrowth assay (nubbin assay)}

The Matrigel outgrowth assay was performed as described by Price and Thompson [65] using a 96-well plate setup. The desired number of cells (titration was done using 250, 500 , and 1000 cells per well) were mixed in $5 \mu \mathrm{l}$ of Matrigel and transferred into each well. The cell and Matrigel mixture was allowed to set by incubating at $37{ }^{\circ} \mathrm{C}$ for 15 minutes. Once the gel was set, $80 \mu \mathrm{l}$ of DMEM supplemented with $10 \%$ FBS was carefully added to each well. The assay was then incubated at $37{ }^{\circ} \mathrm{C}$ for 1 week. The wells were photographed daily, and the morphological changes seen in the cells were assessed and recoded.

\section{Inoculation of severe combined immunodeficiency mice with E-cadherin-modified cell lines}

MDA-MB-468 cells were grown in T175 flasks (Thermo Fisher Scientific, Australia) to approximately 70\% confluence. Cells were trypsinized to a single-cell suspension, washed three times in PBS, and resuspended to $1.33 \times 10^{8}$ 
Table 2 Antibodies used in this study

\begin{tabular}{|c|c|c|c|}
\hline & Species & Source & Catalogue number \\
\hline \multicolumn{4}{|l|}{ Primary antibody } \\
\hline Human E-cadherin & Rabbit & Abcam, Cambridge, UK & Ab15148 \\
\hline Human E-cadherin & Mouse & BD Biosciences, San Jose, CA, USA & 610404 \\
\hline Human vimentin & Mouse & Dako, Glostrup, Denmark & M0725 \\
\hline a-Pan-actin & Mouse & Abcam, Cambridge, UK & Ab14128 \\
\hline Human mitochondrial & Mouse & Thermo Fisher Scientific, Waltham, MA, USA & MA5-12017 \\
\hline Mouse CD31 & Rat & BD Pharmingen, San Diego, CA, USA & 550274 \\
\hline Human HIF-1a & Mouse & BD Biosciences, San Jose, CA, USA & 610958 \\
\hline \multicolumn{4}{|l|}{ Secondary antibody } \\
\hline Antimouse biotin & Rabbit & Dako, Campbellfield, Australia & E0354 \\
\hline Antirabbit biotin & Swine & Dako, Campbellfield, Australia & E0431 \\
\hline Antirat biotin & Goat & Vector Laboratories, Burlingame, CA, USA & BA-9401 \\
\hline Antirabbit Alexa Fluor 594 & Donkey & Molecular Probes, Eugene, OR, USA & R37119 \\
\hline Antimouse Alexa Fluor 488 & Goat & Molecular Probes, Eugene, OR, USA & A11001 \\
\hline \multicolumn{4}{|l|}{ Tertiary label } \\
\hline Streptavidin/HRP & & Dako, Campbellfield, Australia & P0397 \\
\hline
\end{tabular}

HIF Hypoxia-inducible factor

viable cells in $1 \mathrm{ml}$ of PBS. The cell suspension was kept on ice until used for inoculation. All of the experimental procedures pertaining to this section were performed according to the guidelines stipulated by the animal ethics committee (AEC) at St. Vincent's Hospital, Melbourne (AEC protocol number 008/08). Severe combined immunodeficiency (SCID) mice (8-10 weeks old) were obtained from the animal resource center in Perth, Australia. Briefly, the mice were anesthetized with isoflurane, the lower abdominal region of the mouse was cleaned with $70 \%$ ethanol, and a vertical paramedial skin incision of about $1 \mathrm{~cm}$ was made in the lower right abdominal region overlying the mammary fat pad (MFP). The cell suspension (15 $\mu \mathrm{l}$ containing $2 \times 10^{6}$ MDA-MB-468 cells) was injected into the MFP using a 50- $\mu$ l Hamilton syringe. After inoculation of the cells, the incision was closed with two stainless steel wound clips, which were removed once the incision wounds were completely healed. The mice were monitored twice weekly throughout the experiment, and tumor dimensions and body weights were recorded. The volume of the tumor was estimated as width of the tumor squared multiplied by (length of the tumor divided by 2) and expressed in cubic millimeters. Mice were killed when the tumor volume reached $10 \%$ of the body weight. Tissues were harvested after mice were killed by exposing them to a high dose of $\mathrm{CO}_{2}$. The xenograft tumors were removed carefully, weighed, and photographed. One-half of the tumor was then fixed in formalin for histological analysis and IHC. The other half was chopped into small pieces and rapidly frozen in liquid nitrogen for RNA analysis. The lungs were fixed in formalin for histological analysis.

\section{Determining tumor/necrosis ratio}

The tumor/necrosis ratio was assessed among the tumor groups by scanning the hematoxylin and eosin (H\&E)stained slides using Aperio ScanScope ${ }^{\circ}$ slide scanner (Leica Biosystems, Buffalo Grove, IL, USA). The proportion of area representing viable tumor tissue and necrosis was then estimated with JMicroVision software.

\section{Analysis of human clinical data}

All analyses of public and shared E-cadherin datasets were performed using the University of California Santa Cruz Xena program (http://xena.ucsc.edu/).

\section{Statistical analyses}

Repeated measures analysis of variance (ANOVA) and two-way ANOVA with Bonferroni's multiple comparisons posttest or Dunnett's multiple comparisons posttest, one-way ANOVA, Student's paired $t$ tests, log-rank (Mantel-Cox) statistical tests, and Welch's $t$ tests were performed using Prism software. Where " $n$ " is used (as in $n=3$ ), this refers to the number of independent, biologic replicate experiments performed.

\section{Results}

MDA-MB-468 tumors exhibit regions of EMP associated with hypoxia

Consistent with previous results [66], the differential EMP status in these xenograft tumors was demonstrable by double IHC of E-cadherin (Fig. 1a, brown) and vimentin (Fig. 1a, red). Vimentin-positive cells (red color) indicating EMT were clearly seen in two distinct 
Table 3 Primers used in this study

\begin{tabular}{|c|c|c|}
\hline \multicolumn{2}{|l|}{ Primer name } & \multirow{2}{*}{$\begin{array}{l}\text { Nucleotide sequence } \\
\text { CAGAAAACGTGCACATGAGCTGC }\end{array}$} \\
\hline L32 & RT sequence & \\
\hline & Forward sequence (outer nested) & CAGGGTTCGTAGAAGATTCAAGGG \\
\hline & Reverse sequence (outer nested) & CTTGGAGGAAACATTGTGAGCGATC \\
\hline & Forward sequence (inner nested) & GATCTTGATGCCCAACATTGGTTATG \\
\hline & Reverse sequence (inner nested) & GCACTTCCAGCTCCTTGACG \\
\hline \multirow[t]{3}{*}{ Carbonic Anhydrase 9 (for hypoxia validation) } & Random priming used & \\
\hline & Forward & CCTCAAGAACCCCAGAATAATGC \\
\hline & Reverse & CCTCCATAGCGCCAATGACT \\
\hline \multirow[t]{3}{*}{ E-cadherin } & RT sequence & GTCAGCCAGCTTCTTGAAGCGATT \\
\hline & Forward sequence & GCCCTGCCAATCCCGATGAAA \\
\hline & Reverse sequence & GGGGTCAGTATCAGCCGCT \\
\hline \multirow[t]{3}{*}{ Vimentin } & RT sequence & CCGTGAGGTCAGGCTTGGAAA \\
\hline & Forward sequence & GCTTCAGAGAGAGGAAGCCGAAAA \\
\hline & Reverse sequence & CCGTGAGGTCAGGCTTGGAAA \\
\hline \multirow[t]{3}{*}{ Endogenous E-cadherin (CDH1-3'UTR) } & RT sequence & GCACTTGGGGATTCTGGGCTIT \\
\hline & Forward sequence & GTGCCTAAAGTGCTGCAGCCAAA \\
\hline & Reverse sequence & GTACAAACCACGGATCTTGTGTCAGAAA \\
\hline \multirow[t]{3}{*}{ Exogenous E-cadherin (for 468-CDH1 construct) } & RT sequence & GAAAGGACAGTGGGAGTGGCACTIT \\
\hline & Forward sequence & CCTGAACTCCTCAGAGTCAGACAAA \\
\hline & Reverse sequence & GTGGCACCTTCCAGGGTCAAGGAA \\
\hline \multirow[t]{3}{*}{ E-cadherin shRNA (for 468-shCDH1 constructs) } & RT sequence & CCAGCTCAGCCCGAGTGGAAAT \\
\hline & Forward sequence & CCTCCCATCAGCTGCCCAGAAAA \\
\hline & Reverse sequence & СTCTGTCACCTTCAGCCATCCTGTTT \\
\hline \multirow[t]{3}{*}{ Snail 1} & RT sequence & CGCAGACAGGCCAGCTCAGGAAT \\
\hline & Forward sequence & СACATCCTTCTCACTGCCATGGAATT \\
\hline & Reverse sequence & GCTGCCCTCCCTCCACAGAAAT \\
\hline \multirow[t]{3}{*}{ Estrogen Receptor 1} & RT sequence & CCAGGGCCACGCTGGGAAATGAA \\
\hline & Forward sequence & GTTCCAGTGGGCACTGTACTTGGATCTT \\
\hline & Reverse sequence & CAGCTCCATGCCCCAGGGCTAAAT \\
\hline
\end{tabular}

Abbreviations: $R T$ reverse transcription, shRNA Short hairpin RNA

areas of the tumor: at regions of the tumor-stroma interface (blue arrows) and along the tumor-necrosis border (yellow arrows). Cells between these two layers were mainly vimentin-negative and E-cadherin-positive (brown color). Some of the vimentin-positive cells in the tumorstroma interface were also positive for E-cadherin, indicating a hybrid phenotype. The vimentin-positive cells at the invasion front were arranged in thin rows of individual cells interspersed between stromal $(\mathrm{S})$ connective tissue (blue arrow), typical of the invasive lobular carcinoma that lacks E-cadherin [67]. Vimentin-positive cells along the necrosis $(\mathrm{N})$ front were also arranged in a thin border (yellow arrow). Human skin was used as the positive control for both E-cadherin and vimentin staining (Fig. 1a).
We hypothesized that the EMP seen along the tumornecrosis border could be a consequence of HPX, given recent reports of HPX-induced EMT in MDA-MB-468 cells $[68,69]$ in addition to our own in vitro study [70]. To assess HPX in the xenograft tumors, IHC staining of the HPX marker hypoxia-inducible factor- $1 \alpha$ (HIF- $1 \alpha)$ was performed. HIF-1 $\alpha$-positive cells (black arrow) were distributed along the tumor $(T)$-necrosis $(N)$ border only, corresponding to the region containing the vimentinpositive cells (Fig. 1b, black arrow), as also seen in islands of tissue surrounding vessels within the necrotic region (Additional file 1: Figure S1a). These combined results associate the necrotic interface EMT with HPX and suggest an HPX-independent EMT induction mechanism inducing vimentin at the tumor-stroma border. 


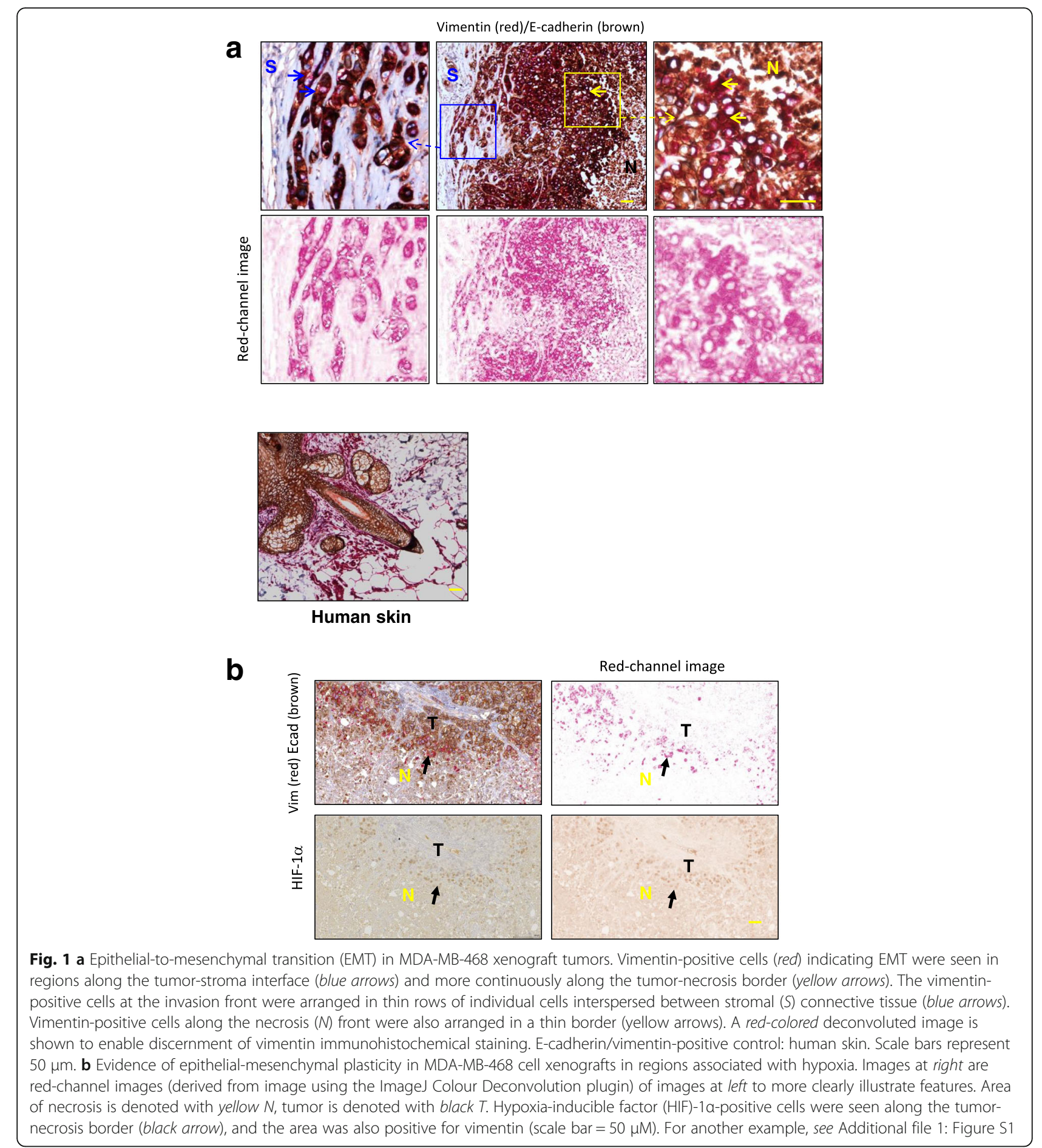

\section{Metastases of MDA-MB-468 xenograft primary tumors exhibit evidence of epithelial differentiation, consistent with MET}

An interesting histological feature observed in the MDA-MB-468 tumors was the existence of carcinoma in situ-like areas (Fig. 2a). These spherical tumor masses were surrounded by connective tissue fibers, presenting as encapsulated tumor. They were generally located toward the periphery of the tumors and were composed of cohesive tumor cells that strongly expressed E-cadherin, in contrast to the neighboring vimentin-positive cells at the invasive front of the tumor. As shown in Fig. 2a(i) and (ii), the pattern of Ki-67 staining in the MDA-MB468 tumors did not correlate with either vimentin or E- 

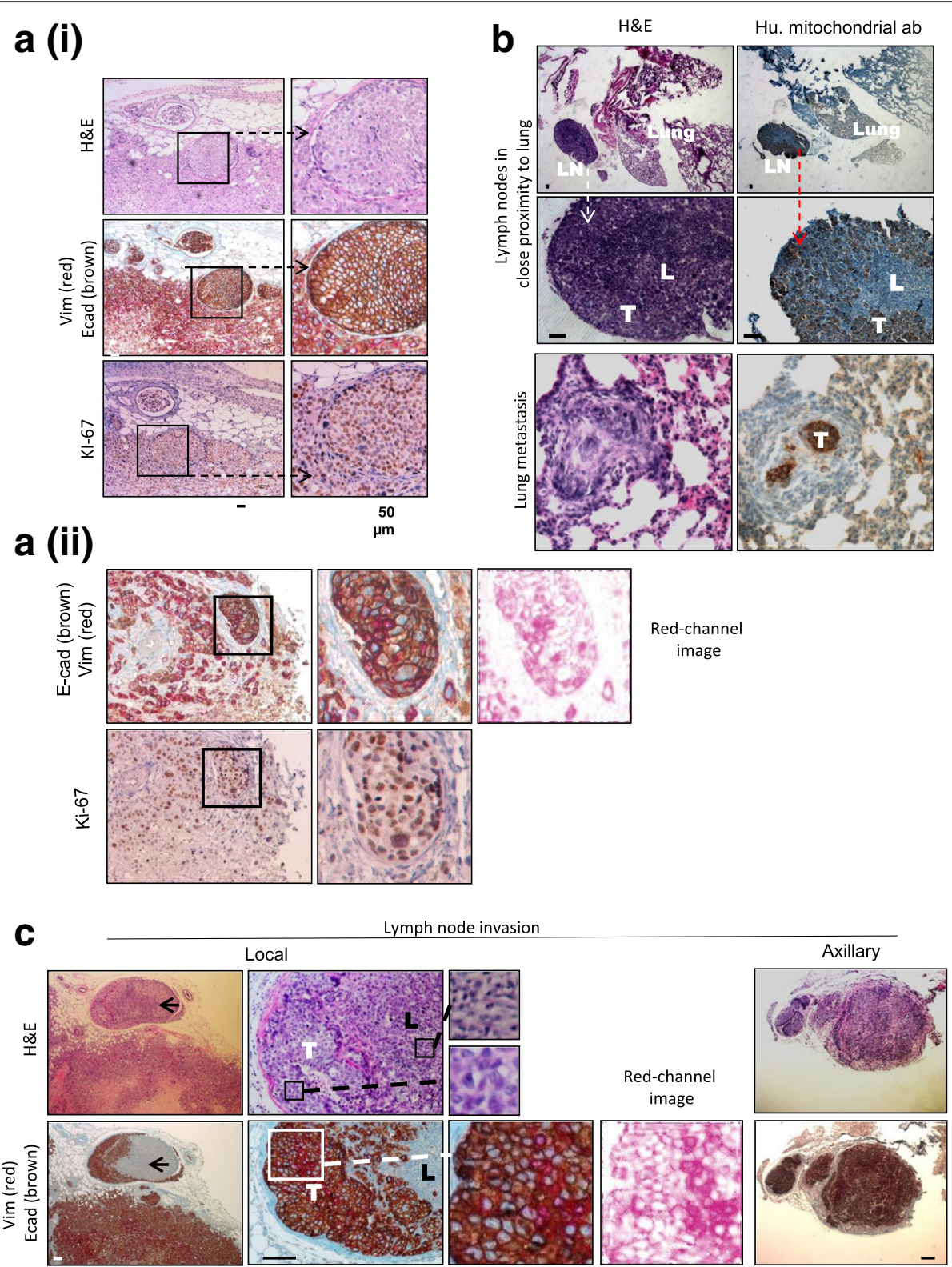

Fig. 2 Pronounced expression of E-cadherin was observed in MDA-MB-468 xenograft metastases. a (i) and (ii) Similarity of features of MDA-MB468 xenograft tumors. Red-channel image is shown for simplicity of vimentin staining. b Metastatic tumor cells in lymph nodes (LNs) and lungs. Positive staining for an antihuman mitochondrial antibody confirmed that tumor cells were of human origin ( $T$ ), whereas mouse lymphocytes (L) were not stained. Tumor cells in the lung demonstrated E-cadherin expression but not vimentin. $\mathbf{c} L N$ invasion. Black arrows indicate invasion of E-cadherin and vimentin-expressing tumor cells to the adjacent LNs (T). Red-channel image is shown for clarity of vimentin staining. Tumor cells in axillary nodes stained homogeneously for E-cadherin. Lymphoid tissue $(L)$ did not stain for either E-cadherin or vimentin, confirming its murine origin. All scale bars $=50 \mu \mathrm{m}$, except for axillary LN images, where scale bar represents $100 \mu \mathrm{m}$. H\&E Hematoxylin and eosin

cadherin staining in the tumor proper or in the zones of EMT, and it was expressed in approximately $90 \%$ of all cells in the growing tumor.

As shown in Fig. 2b, metastatic tumor cells were seen in some LNs within close proximity of the lungs and within the lungs themselves, with positive staining with a human-specific mitochondrial antibody confirming that these cell clusters were of human origin. Lung micrometastases were seen across all the groups, with a marked trend toward E-cadherin-expressing groups (Table 4).

MDA-MB-468 tumor cells were detected in LNs associated with the lungs and as micrometastases within the lungs themselves (Fig. 2c). Confirmation of the presence of cells of human origin was obtained by a humanspecific, antimitochondrial antibody $(T)$ with mouse 
Table 4 Incidence of lung metastases across the tumor groups

\begin{tabular}{llll}
\hline Group & $\begin{array}{l}\text { Number } \\
\text { observed }\end{array}$ & $\begin{array}{l}\text { With lung } \\
\text { metastasis }\end{array}$ & $\begin{array}{l}\text { Percentage of } \\
\text { metastasis }\end{array}$ \\
\hline 468-shSCR & 10 & 7 & 70 \\
468-shCDH1-B & 10 & 3 & 30 \\
468-shCDH1-D & 10 & 5 & 50 \\
468-pcDNA3 & 9 & 5 & 55.6 \\
468-CDH1 & 10 & 7 & 70 \\
\hline
\end{tabular}

Fisher's exact test was used to determine statistical significance

unstained $(L)$ (Fig. 2c, inset). Most of the cells demonstrated E-cadherin expression; however, none were positive for vimentin, indicating an epithelial phenotype. Both local and distant LN (axillary) metastases were observed in a subset of mice $(n=4)$ with MDA-MB-468 xenograft tumors (Fig. 2c). The tumor cells that invaded into the local LNs generally displayed a heterogeneous expression pattern of E-cadherin and vimentin, as shown in the enlarged image, an indication that these cells displayed a spectrum of EMP, although epithelial cells with strong E-cadherin expression were the most abundant. In contrast, tumor cells in the axillary nodes stained homogeneously for E-cadherin. These results support a requirement for epithelial phenotype for secondary colonization by metastasized tumor cells and support the possibility of MET.

\section{Creation and validation of E-cadherin-modified MDA-MB- 468 cell lines}

Given that EMP was observable in MDA-MB-468 cells grown in vivo in xenografts (Fig. 1) and that E-cadherin was a strong feature of secondary deposits (Fig. 2), we sought to enforce either stable epithelial or mesenchymal status in the MDA-MB-468 cell system by directly manipulating E-cadherin expression positively or negatively, respectively, and to examine MDA-MB-468 cell behavior in vivo. Manipulation of E-cadherin has been used effectively for EMP studies in HMLE human epithelial mammary cells [71], human head and neck squamous carcinoma cells [72], and dog kidney and mouse mammary carcinoma cells [73].

MDA-MB-468 cells were transfected with either fulllength human E-cadherin (468-CDH1) or four shRNA variants (468-shCDH1-A-468-shCDH1-D) and a "scrambled" nontargeting hairpin control (468-shSCR) against $\mathrm{CDH} 1$, as described in the "Methods" section above. Each transfectant/transductant was characterized by Western blotting and qPCR (Fig. 3a and b).

Western blotting (Fig. 3a, i) confirmed an elevated Ecadherin protein level in 468-CDH1 cells compared with 468-pcDNA3 cells. Gene-specific qPCR analysis (Fig. 3a, ii) was performed using primers designed to detect endogenous versus exogenous forms of E-cadherin (see
Table 3 for primer sequences). The collective expression of both exogenous and endogenous E-cadherin was detected using a more general primer set (i.e., "E-cad overall" as labeled in Fig. 3a, ii). The endogenous E-cadherin messenger RNA (mRNA) was assessed using a primer pair targeting the 3' untranslated region of the $\mathrm{CDH} 1$ gene. Both the cell types examined in Fig. 3a(iii) expressed endogenous E-cadherin; however, the 468CDH1 cells also expressed exogenous E-cadherin, which contributed to the E-cadherin measured in the overall primer set, confirming the successful transfection of fulllength E-cadherin into MDA-MB-468 cells. Approximately 130 -fold induction $\left(2^{-\Delta \Delta \mathrm{Ct}}\right)$ was observed in the expression of overall E-cadherin message, which was statistically significant in 468-CDH1 cells compared with 468-pcDNA3 cells, with no significant change in endogenous E-cadherin expression. Vimentin expression in 468-CDH1 cells remained unchanged from the basal level, despite their forced epithelial status (Fig. 3a, ii).

Characterization of shRNA variants compared with the scrambled control by Western blotting showed that the 468-shCDH1-B and 468-shCDH1-D cells expressed the least E-cadherin protein, and the least was seen in 468shCDH1-C cells (Fig. 3b, $i$ ). A comparable pattern was also seen by qPCR (Fig. 3b, ii). As shown in Fig. 3c, the best E-cadherin knockdown confirmed by qPCR (468shCDH1-B) exhibited further upregulated vimentin expression and E-cadherin repression above that of the SCR short hairpin control when the cell lines were treated with epidermal growth factor (EGF) for 5 days. The EMT-related genes serpin family E member 1 (SERPINE1) and FOSL1 selected for analysis were based upon a previously published gene set consistently upregulated in our hands in MDA-MB-468 cells that underwent EMT after treatment with either EGF or HPX [70]. Snail1 was selected because it was shown to be upregulated by EGF in this previous study. All EMT genes were upregulated by EGF in all cell lines tested, except for SERPINE1, which was downregulated in 468-shCDH1-B cells. Immunofluorescence for vimentin at this 5-day treatment time point (Fig. 3c, ii) reflected the induction by EGF observed by qPCR.

\section{Forced E-cadherin expression blocked cellular invasion, whereas its knockdown stimulated invasion and reduced proliferative growth}

We examined the invasive potential and proliferative rate of the various E-cadherin-modified cells in culture (Fig. 4).

Each cell line was assessed in the Transwell chemomigration assay. The number of migrated 468-CDH1 cells was significantly lower than the control 468-pcDNA3 control cells, indicating that overexpression of Ecadherin in MDA-MB-468 cells significantly reduced 


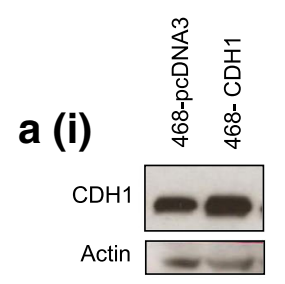

(ii)

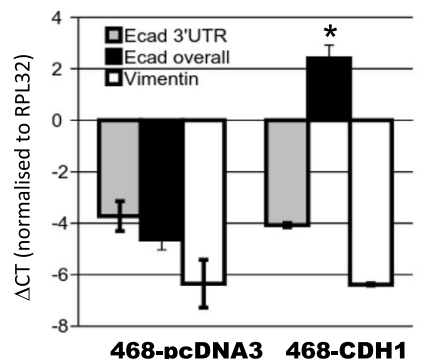

c (i)

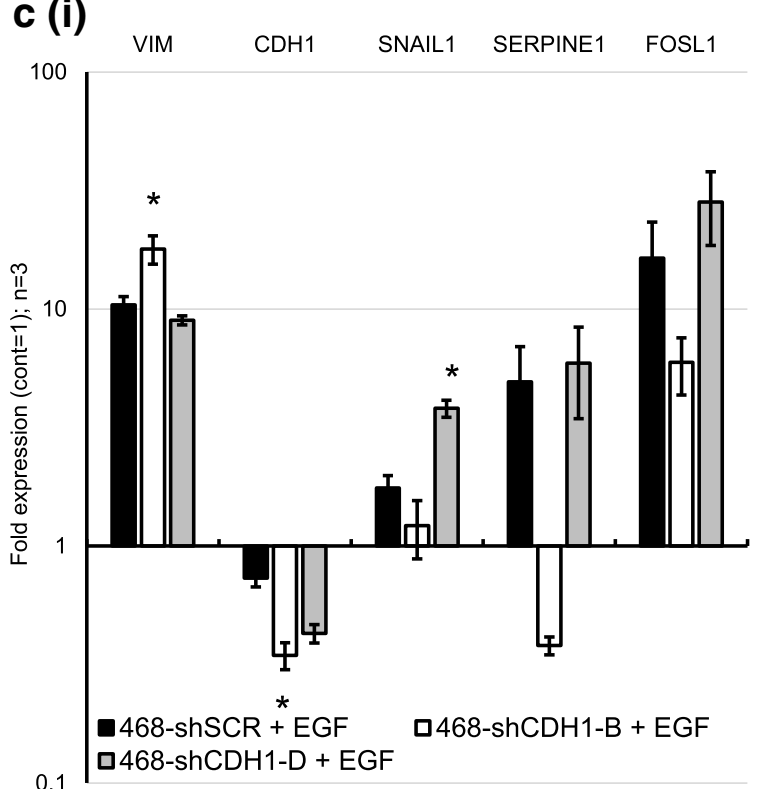

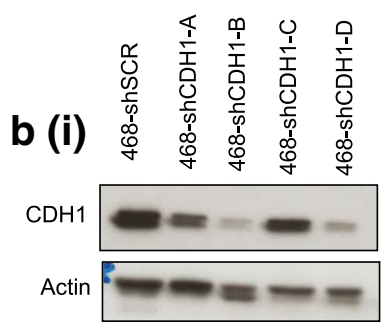
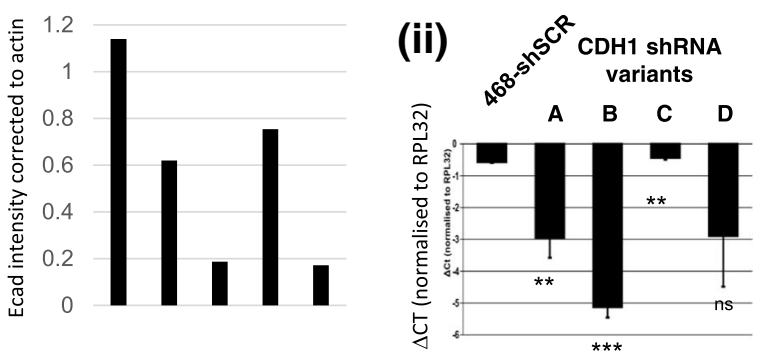

(ii) Vimentin/DAPI

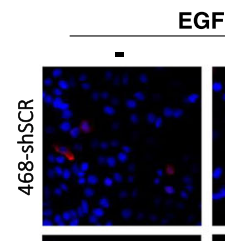

GF

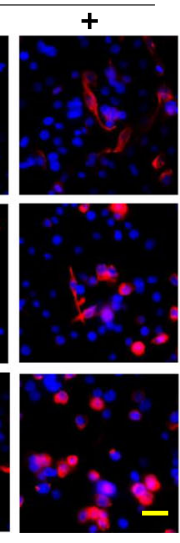

Fig. 3 Validation and characterization of E-cadherin-manipulated MDA-MB-468 cell lines. E-cadherin-overexpressing (a) and short hairpin RNA (shRNA)-transduced (b) MDA-MB-468 cells assessed by (i) Western blotting and (ii) quantitative polymerase chain reaction (qPCR) (error bars represent SEM in three independent experiments). Statistical significance was determined by two-tailed, paired $t$ test; ${ }^{* * *} p<0.0001,{ }^{* *} p<0.01$ and ${ }^{*} p<0.05$. c (i) Treatment of 468-shCDH1 cells with epidermal growth factor (EGF) to assess their ability to undergo epithelial-to-mesenchymal transition (EMT) by qPCR for various EMT genes. Fold expression (from the control) is shown, where control = 1 and $y$-axis is on a logarithmic scale. Error bars represent SEM derived from three independent experiments. (ii) Matching vimentin immunofluorescence (combined with nuclear 4',6-diamidino-2-phenylindole [DAPI] stain) of the cells at day 5 time point (scale bar represents $50 \mu \mathrm{m}$ ). $\Delta$ CT Cycle threshold change, UTR Untranslated region

their potential to migrate as single cells (Fig. 4a, $i$ ). Compared with the 468-shSCR cells, the number of migrated 468-shCDH1-B cells was significantly higher (Fig. 4a, ii). Similarly, a higher rate of cell migration was apparent in 468-shCDH1-D compared with the vector control, although this was not statistically significant. The results highlight that the functional knockdown of E-cadherin achieved by shRNA in MDA-
MB-468 cells led to an increase in migratory capacity. Similarly, the 468-shCDH1-B and 468-shCDH1-D cells were more invasive, as shown by greater Matrigel outgrowth (Fig. 4b). In this assay, cells were evenly dispersed in a nubbin of Matrigel that was formed on a Matrigel-coated well in a 96-well setup, topped with FBS-supplemented DMEM and incubated at $37{ }^{\circ} \mathrm{C}$. By the seventh day of the assay, a portion of 468- 


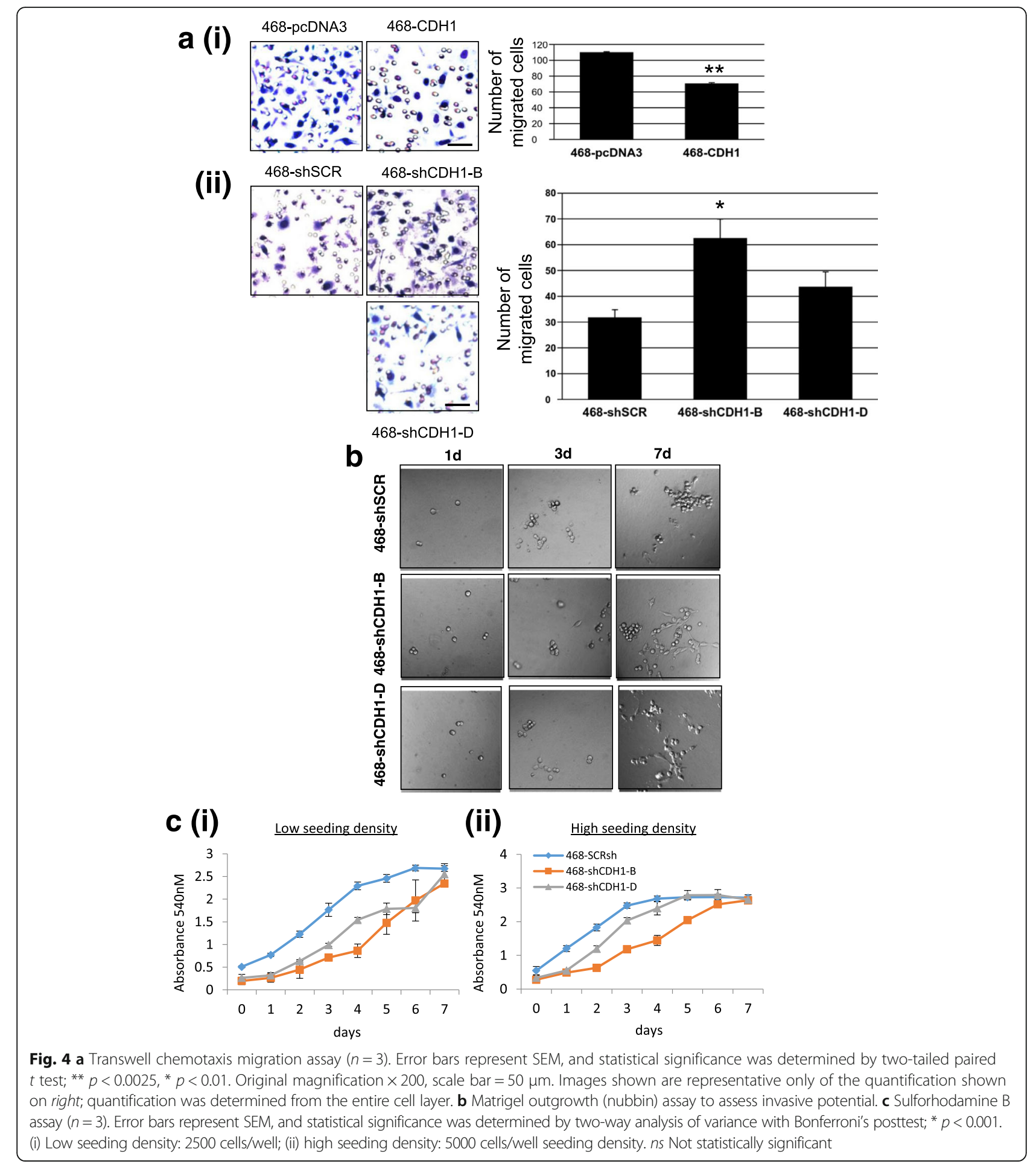

CDH1shRNA-B and 468-CDH1shRNA-D cells had invaded through the $3 \mathrm{D}$ culture coating to the floor of the well, where they displayed an elongated phenotype resembling mesenchymal cells. The noninvaded cells remained trapped in the Matrigel and formed a spheroidal cluster of cells similar to the cell clusters formed by 468-SCRshRNA cells. These results show that knockdown of E-cadherin in MDA-MB-468 cells enhanced their invasive potential.

The SRB assay was performed to compare the rates of cell proliferation. To determine if density affected this, the cells were seeded at two different cell densities (2500 and 5000 cells per well; see Fig. 4c, $i$ and $i$, respectively). No significant difference was observed between 468- 
pcDNA3 and 468-CDH1 cell lines with respect to proliferative rate (data not shown); however, 468-shCDH1-B and 468-shCDH1-D cells proliferated at noticeably lower rates than the 468-shSCR control when plated at low density (Fig. 4c, i). At twice the seeding cell density, an initial lag was observed in the proliferative rate of 468shCDH1-B and 468-shCDH1-D cells, which gradually disappeared by the sixth day (eighth day after cell seeding). The results reveal that E-cadherin silencing has an inhibitory effect on cell proliferation, which was more prominent under sparse culture conditions.

\section{E-cadherin-manipulated tumors grew slower than their respective controls}

We tested the primary tumor growth and metastatic competence of the E-cadherin-manipulated cell lines by orthotopically inoculating them into the MFPs of SCID mice and subsequently analyzing the primary xenograft tumor growth and extent of lung metastases. Details of the cell groups used in the in vivo experiments are listed in Table 5. No significant difference was detected between the 468-shSCR and 468-pcDNA3 groups from days 80 to 119 (data not shown). As shown in Fig. 5a(i), the 468-CDH1 xenografts appeared larger than the 468pcDNA3 ones at all time points and were significantly larger on day 107, as determined by two-way ANOVA with Bonferroni's posttest.

The rate of tumor growth was more markedly different among the 468-shSCR, 468-shCDH1-B, and 468shCDH1-D groups (Fig. 5a, ii). Although no obvious changes were observed between 468-shSCR and 468shCDH1-B at the earlier time points, the tumor volume was significantly lower in 468-shCDH1-B than in the vector control 468-shSCR from 97 days onward postinoculation. A similar trend was also detected between the 468-shSCR and 468-CDH1shRNA-D groups, although the difference in tumor growth was not seen until

Table 5 Summary of the in vivo experiments

\begin{tabular}{lllll}
\hline Group & $\begin{array}{l}\text { Number of mice } \\
\text { inoculated }\end{array}$ & Tumors & $\begin{array}{l}\text { Died } \\
\text { early }\end{array}$ & $\begin{array}{l}\text { Tissue } \\
\text { harvest }\end{array}$ \\
\hline 468-WT & 13 & 13 & 0 & 13 \\
468-shSCR & 13 & 13 & 0 & 13 \\
468-shCDH1-B & 13 & 13 & 0 & 13 \\
468-shCDH1-D & 13 & 13 & 01 & 12 \\
468-pcDNA3 & 12 & 09 & 0 & 12 \\
468-CDH1 & 12 & 12 & 0 & 12 \\
\hline
\end{tabular}

sh Short hairpin, SCR Scrambled, WT Wild type

The E-cadherin-modified MDA-MB-468 cell lines were orthotopically inoculated to the right mammary fat pads of severe combined immunodeficiency mice ( $n=12-13$ per group). The groups inoculated with wild-type MDA-MB-468 (468-WT), 468-shSCR, 468-shCDH1-B, 468-shCDH1-D, and 468-CDH1 developed tumors in all mice. In the 468-pcDNA3 group, 9 of 12 mice developed tumors. One mouse from the 468-shCDH1-D group died before harvest as a result of non-tumor-related causes
105 days postinoculation. No difference was seen between 468-shCDH1-B and 468-shCDH1-D for up to 136 days postinoculation, after which 468-shCDH1-D tumors demonstrated a significantly higher tumor growth rate than 468-shCDH1-B (Fig. 5a, ii; Additional file 2: Figure S2a). The results revealed that the tumor growth rate in $\mathrm{E}$ cadherin-knockdown groups was significantly slower than their vector control, and this appeared to be dosedependent because 468-shCDH1-B had a more complete knockdown than 468-shCDH1-D. Despite these marked changes in tumor growth, no difference was observed in Ki-67 staining in tumors from the E-cadherin-modified cell lines (Additional file 3: Figure S3).

\section{E-cadherin-knockdown tumors are less necrotic}

Standard histopathological assessment of the xenografts was performed by $H \& E$ staining. The tumors from all groups except 468-shCDH1-B were composed of a central necrotic area surrounded by a thin rim of viable tumor tissue (Fig. 5b, i). A common feature detected in these tumors was the presence of small islands of viable cells surrounding a central blood vessel, embedded within the central necrotic region. Tumors from the 468-shCDH1-B group, regardless of tumor size, were composed mainly of viable tumor tissue with only very small areas of necrotic foci (Fig. 5b, $i$ ). The percentage of necrosis exceeded that of viable tumor tissue across all groups except 468shCDH1-B, where the amount of viable tumor tissue was considerably higher than the extent of necrosis (Fig. 5b, ii). The proportion of viable tumor tissue was significantly higher in 468-shCDH1-B tumors than in any other group.

\section{Tumor microvasculature is more developed in 468- shCDH1-B xenografts}

We investigated whether differences in necrotic area between the various tumor types (Fig. 5b) was due to altered vasculature using IHC staining of the vascular endothelial marker CD31/platelet endothelial cell adhesion molecule1 (Fig. 6a, left panel). In 468-shCDH1-B tumors, the majority of blood vessels were larger with well-organized architecture, as compared with the less substantial microvasculature observed in the tumors across all other groups, whereas no statistically significant change was detected in the number of blood vessels across the tumor groups (Fig. 6b). All tumor groups except 468-shCDH1-B displayed positive HIF-1 $\alpha$ staining (Fig. 6a, right panel), consistent with HPX occurring within these tumors. Where seen, these hypoxic regions correlated with vimentin positivity (data not shown), as was originally observed for WT MDA-MB-468 tumors (Fig. 1a).

E-cadherin knockdown in human breast cancer cell line xenografts has been shown to decrease tumor growth due to impaired HIF-1 $\alpha$ expression and subsequent ability to metabolize glycogen as an energy source 

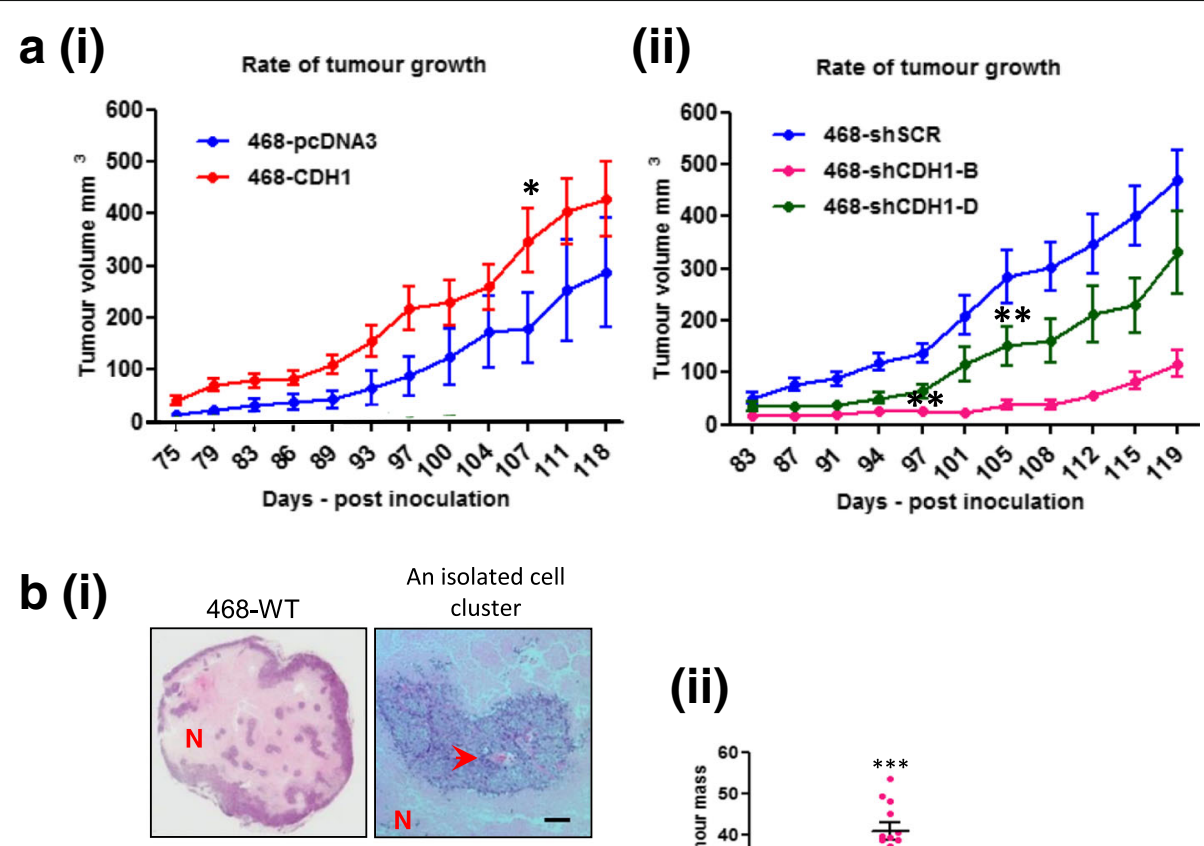

(ii)
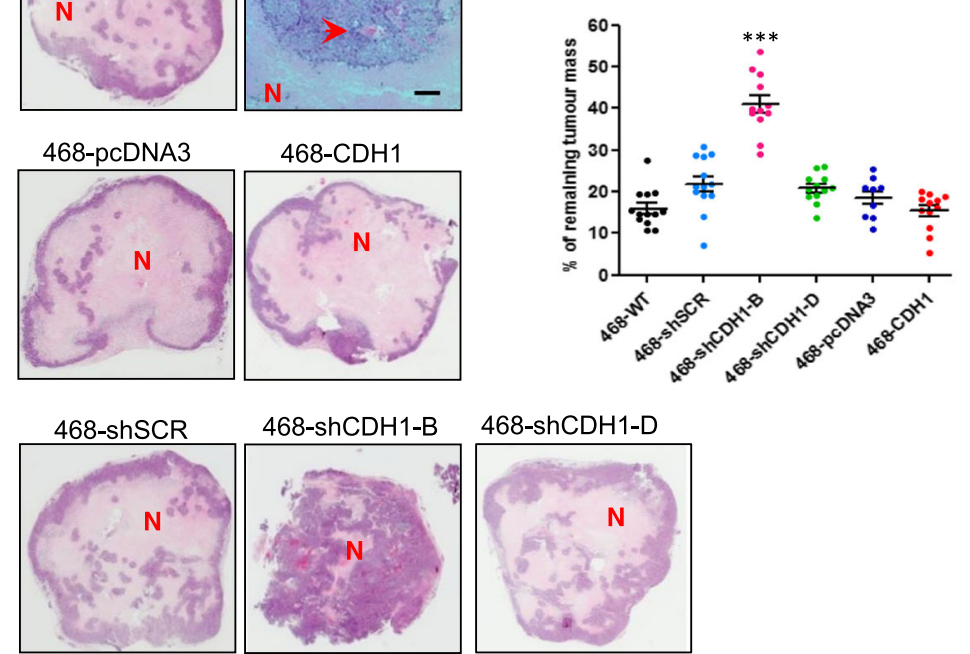

Fig. 5 a Rate of xenograft tumor growth. Individual tumor volumes from each mouse from each group were averaged and plotted against the number days postinoculation. Statistical significance was determined by two-way analysis of variance (ANOVA) with Sidak's posttest; ${ }^{* *} p<0.001$, ${ }^{*} p<0.05$. (i) E-cadherin overexpression group. (ii) E-cadherin knockdown group. $\mathbf{b}$ The tumor/necrosis ratio. (i) Hematoxylin and eosin staining of xenograft tumors, low magnification. $N$ Necrotic area. Blood vessels are indicated by red arrowhead. Scale bar $=50 \mu \mathrm{m}$. (ii) Percentage of viable tumor tissue/remaining tumor mass. Statistical significance was determined by one-way ANOVA; ${ }^{* *} p<0.001$

[74]. To determine whether the 468-shCDH1-B tumors did not express HIF-1 $\alpha$ because of E-cadherin knockdown or whether the cells simply did not experience HPX in vivo, we cultured these cells in hypoxic conditions in vitro and assessed HIF- $1 \alpha$ expression. As shown in Fig. 6c, 468-shCDH1-B and 468-shCDH1-D cells showed induction of the HIF- $1 \alpha$ gene-regulated gene carbonic anhydrase 9 (CAIX) under HPX to a level similar to that of the SCR control, indicating that the hypoxic response was still intact, at least in vitro.

\section{EMT in xenograft tumors from E-cadherin-manipulated MDA-MB-468 cells}

As seen in WT tumors (Fig 1a), in all tumors except 468-shCDH1-B and to some extent 468-shCDH1-D, vimentin-positive cells were observed at the invasion front along the tumor-stroma border and also at the tumor-necrosis border, indicative of EMP (Fig. 7a). Generally, as seen in the MDA-MB-468 WT tumors, the cells at the invasive front of the various xenograft tumors appeared to be arranged in thin rows in "Indian file" formation, interspersed among the stromal connective tissue. In addition, some individual cells were separated from the main tumor mass and located at the extreme periphery of the invasive front (indicated by blue arrow in 468-WT in vivo vimentin-E-cadherin lowpower image in Fig. 7a). The majority of the cells at the invasive front expressed vimentin, indicating EMT in this area, whereas some of the cells coexpressed both vimentin and E-cadherin, highlighting the existence of a 

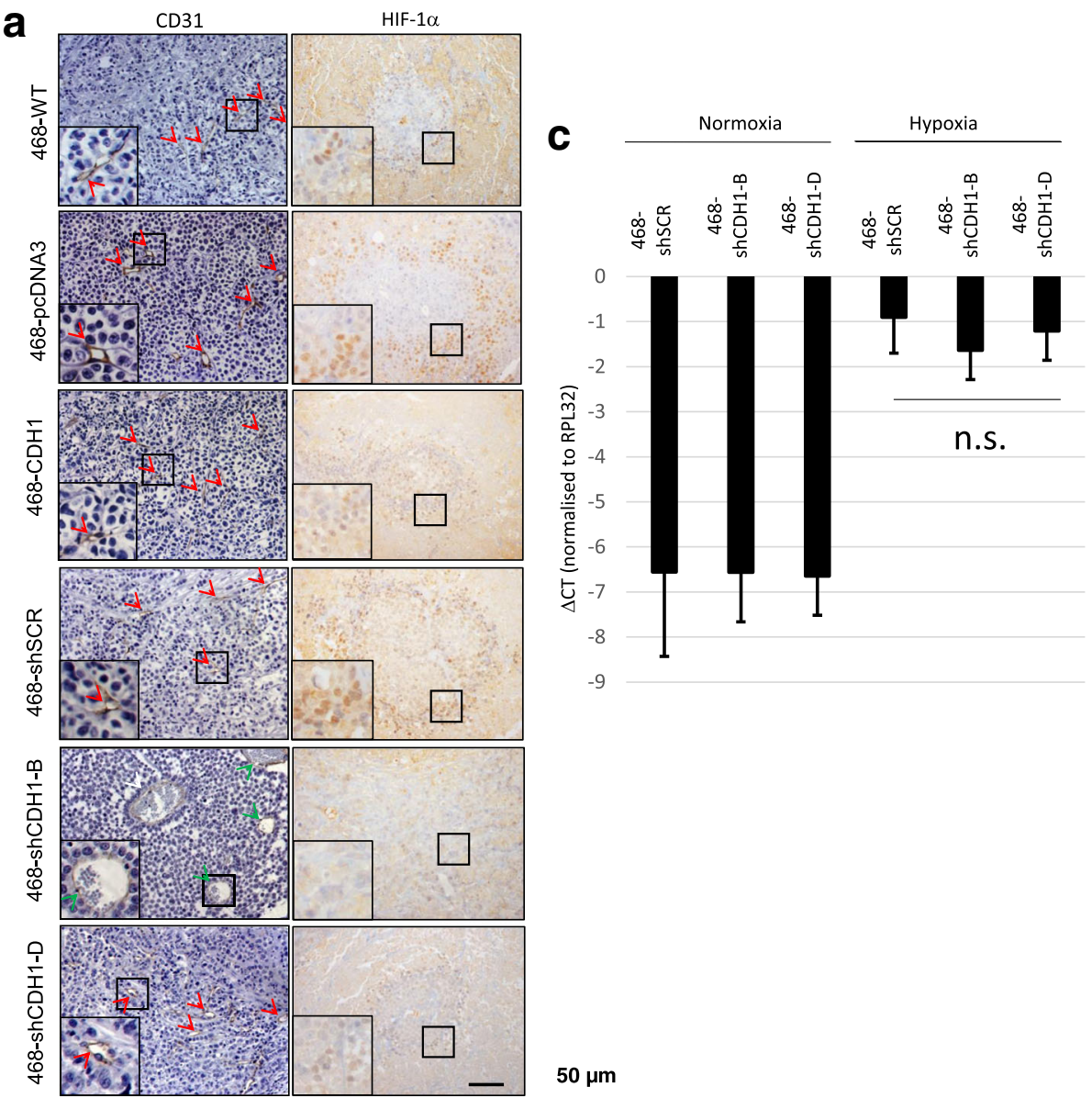

b

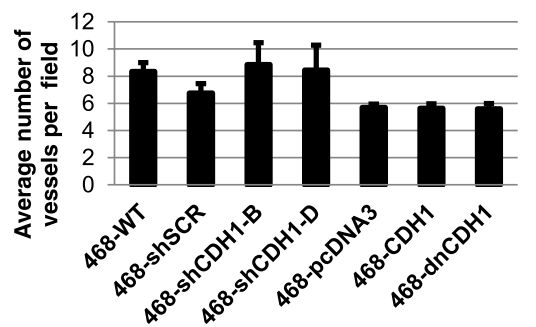

Fig. 6 a Immunohistochemistry for CD31 (left panel), with smaller vessels indicated by red arrowheads and larger vessels indicated by green arrowheads. $\mathbf{b}$ Plot of the average number of CD31-stained blood vessels in five random microscopic fields (original magnification $\times 200$ ) per tumor. Statistical significance was assessed by one-way analysis of variance (no difference across groups). c. Quantitative polymerase chain reaction data for hypoxic indicator gene carbonic anhydrase 9 (CAIX) $(n=3)$. Error bars represent SE. $\Delta C T$ Cycle threshold change, SCR Scrambled, WT Wild type

hybrid cell state able to respond quickly to external stimuli [75]. However, none of the cells at the invasive front demonstrated HIF- $1 \alpha$ positivity, indicating a lack of HPX in this region (data not shown, but Fig. 1a is representative of these results). These observations support the existence of EMP at the invasive front, which is not a result of HPX.

In contrast, E-cadherin was expressed strongly in epithelial cells located in the tumor proper, in between the vimentin-positive borders, in 468-WT, 468shSCR, 468-pcDNA3, and 468-CDH1 tumors (Fig. 7a).
Although the E-cadherin was overexpressed in 468CDH1 cells in vitro (mRNA) (Fig. $3 \mathrm{~s}$, ii), no visible difference was seen in the intensity of E-cadherin staining between $468-\mathrm{CDH} 1$ and the vector control 468-pcDNA3 tumors; however, the ability to distinguish the two colors as separate entities (i.e., Ecadherin and vimentin) in the 468-CDH1 tumors did appear somewhat compromised (Fig. 7b). Vimentin induction in these tumors was not blocked, however, which was unexpected. A few areas of E-cadherinexpressing cells were seen in both 468-shCDH1-B 


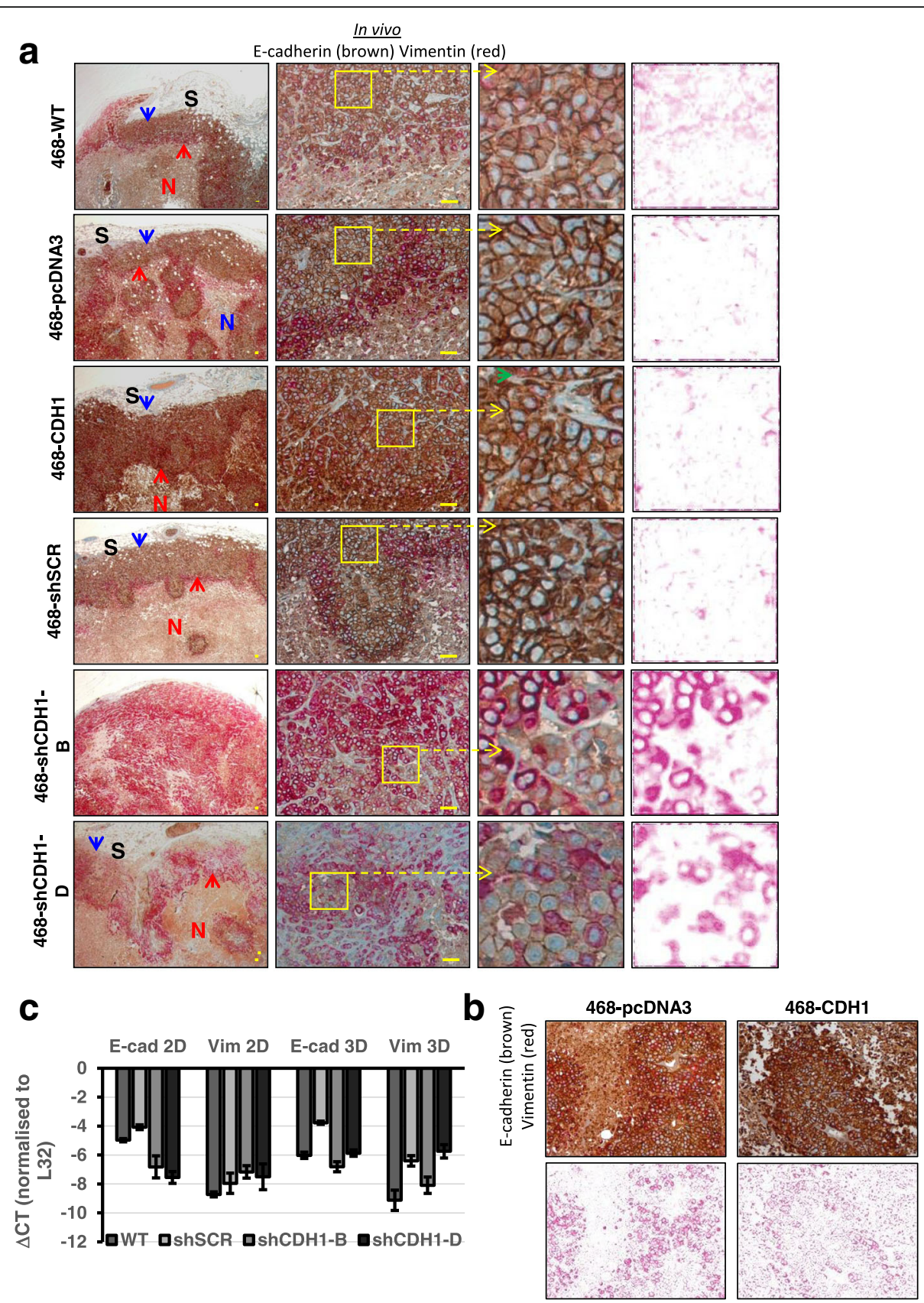

Fig. 7 a Epithelial-mesenchymal plasticity status in vivo as xenografts in mice. E-cadherin was assessed by double-immunohistochemistry (IHC) of E-cadherin (brown) and vimentin (red). Vimentin-positive cells at tumor-stroma interface are indicated by blue arrowheads, and at tumor-necrosis border they are indicated by red arrowheads. Red-channel images are shown for vimentin $I H C$ clarity. All scale bars $=50 \mu m$. $\mathbf{b}$ Enlargement of 468-pcDNA3 and 468-CDH1 tumors showing differences in vimentin-E-cadherin staining. c Quantitative polymerase chain reaction expression of the same modified cells grown in 2D versus 3D. $\Delta C T$ Cycle threshold change, SCR Scrambled, WT Wild type

and 468-shCDH1-D tumors; however, this appeared very weak compared with the 468-shSCR staining. Conversely, vimentin-expressing cells in the 468$\mathrm{CDH} 1$ tumors were prominent at the tumor-stroma border, with one vimentin-positive cell being visible at high power (468-CDH1 high-power image shown in Fig. 7a, green arrow).

\section{E-cadherin-knockdown cells displayed EMT in vivo}

In 468-shCDH1-B and 468-shCDH1-D tumors, the majority of the cells showed strong vimentin staining, indicating widespread EMT in these tumors (Fig. 7a). This is in contrast to the in vitro findings with these cells, where vimentin mRNA was not induced constitutively after E-cadherin reduction (Fig. 3c, comparing no EGF controls). To 
determine whether global induction of vimentin in these E-cadherin-knockdown tumors was due to the 3D state in vivo, we cultured each of the control and sh-CDH1 cells in 3D Matrigel compared with 2D monolayer cultures. We confirmed the lack of vimentin mRNA induction seen in 2D (Fig. 3) and found no further stimulation when the cells were cultured in the 3D environment (Fig. 7c).

The increased in vivo expression of vimentin protein by IHC in 468-shCDH1-B tumors corresponded with upregulated expression of vimentin in matching xenograft tumor RNA (Fig. 8). SNA1 was also significantly upregulated in these tumors. This correlated with a significant downregulation of the estrogen receptor alpha (ESR1), a known Snail1 transcriptional target for repression [76].
SNA1 was variably expressed in a pattern similar to that observed for vimentin, where it was induced in vivo in the E-cad-knockdown tumors but not in vitro, and ESR1 followed suit (Fig. 8). Inhibin, beta A (INHBA) and $L A M C 2$ were also upregulated in the E-cadherinknockdown 468 lines grown in vivo, whereas this was not seen when the cells were plated in 2D culture, and FOSL1 was more highly expressed in vivo (Fig. 8).

E-cadherin was expressed in tumor emboli located within local vasculature, regardless of E-cadherin manipulation status

All WT, 468-SCR, and 468-pcDNA3 groups displayed features similar to those shown in Fig. 2. E-cadherin was

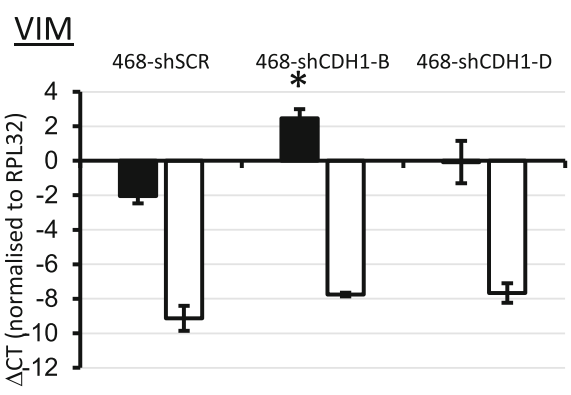

INHBA

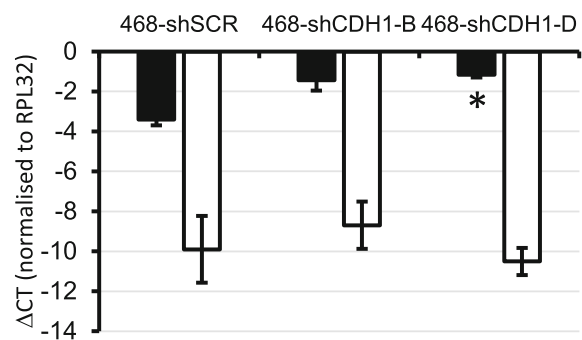

LAMC2

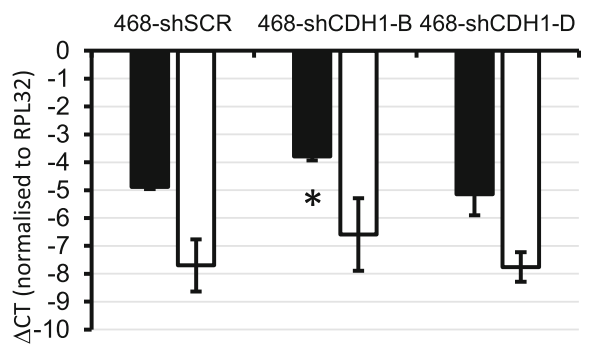

\section{SNAI1}

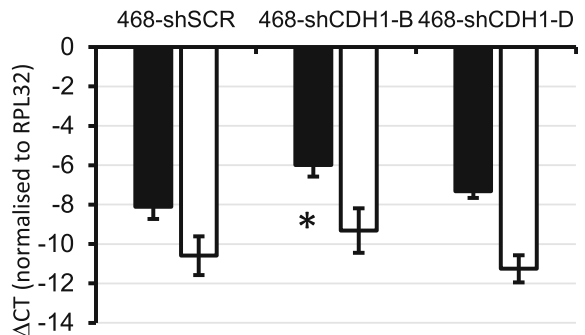

\section{ESR1}

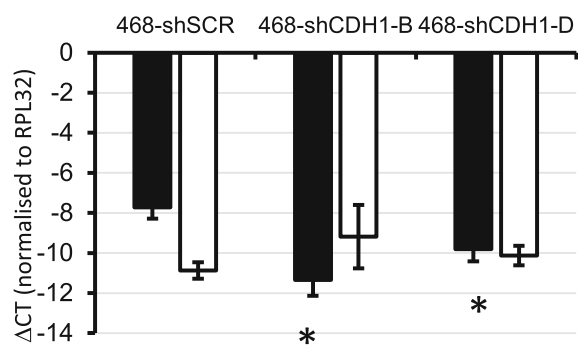

FOSL1

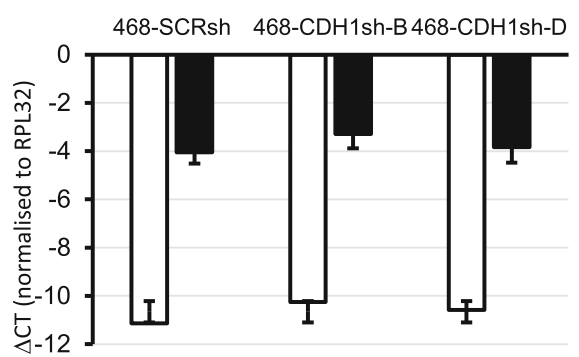

Fig. 8 Quantitative polymerase chain reaction gene expression analyses of 468-shCDH cell xenografts (in vivo) versus plated in 2D culture (in vitro). Results shown are average expression of RNA extracted from three tumors or from three biological replicates of cells plated in 2D. Error bars represent SE. Significance was set at $p<0.05$ and is indicated by asterisk and determined by Student's paired $t$ test (compared with 468-shSCR control). $\Delta C T$ Cycle threshold change, SCR Scrambled, WT Wild type, ESR1 Estrogen receptor alpha, INHBA Inhibin, beta A, SNAII Snail family transcriptional repressor 1 
homogeneously expressed in all groups, except for the 468-shCDH1-B and 468-shCDH1-D tumors, where it was expressed at a less intense level than the control and in a heterogeneous pattern (Fig. 9a, lower right panel). Although local lymphovascular invasion (LVI) was seen across all the tumor groups, no clear association was detected between LVI and the E-cadherin status of the primary xenograft (Table 6). Generally, LVI was more apparent in larger tumors, except for the 468shCDH1-B and 468-shCDH1-D groups, where the LVI was clearly seen even with smaller primary tumors (Fig. 9c).
Table 6 Local lymphovascular invasion

\begin{tabular}{llllc}
\hline Group & $\begin{array}{l}\text { Number of mice } \\
\text { inoculated }\end{array}$ & $\begin{array}{l}\text { With } \\
\text { tumors }\end{array}$ & $\begin{array}{l}\text { With local } \\
\text { invasion }\end{array}$ & $\begin{array}{c}\text { Percentage } \\
\text { of invasion }\end{array}$ \\
\hline 468-shSCR & 13 & 13 & 8 & 61.5 \\
468-shCDH1-B & 13 & 13 & 8 & 61.5 \\
468-shCDH1-D & 12 & 12 & 11 & 91.7 \\
468-pcDNA3 & 12 & 9 & 5 & 41.7 \\
468-CDH1 & 12 & 12 & 11 & 91.7 \\
\hline
\end{tabular}

Local invasion of the lymphovascular spaces was a common feature in many tumors across all the groups, and no clear association was detected between

it and the E-cadherin status of the primary tumors
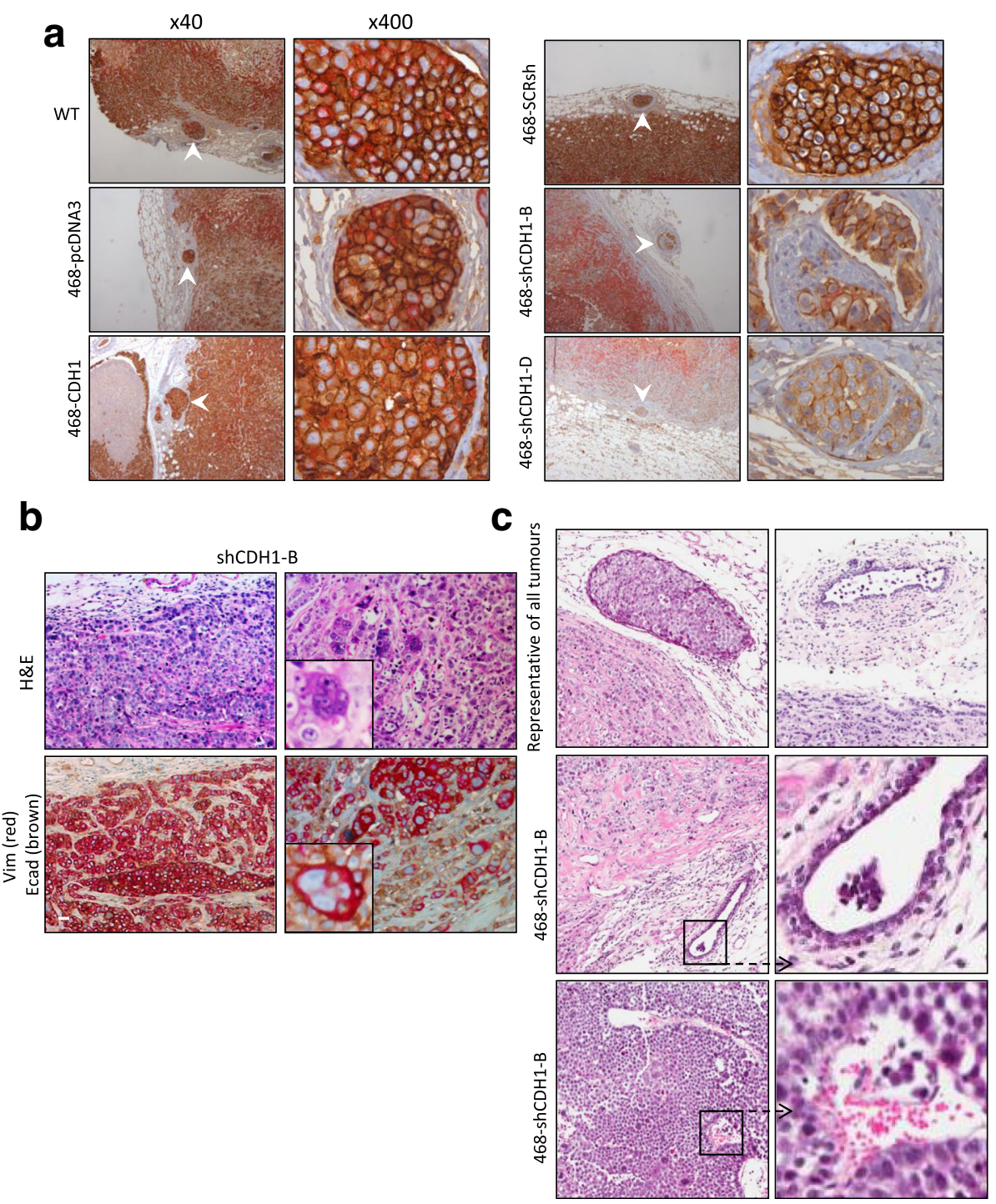

Fig. 9 a. Dual immunohistochemistry staining (red = vimentin, brown = E-cadherin) of CDH1-modified cell line xenografts. Original magnification $\times$ 40 and $\times 400$. $\mathbf{b}$ Closer inspection of 468-shCDH1-B (top, hematoxylin and eosin [H\&E] staining; bottom, dual E-cadherin and vimentin staining) with higher-magnification inset. Scale bar $=50 \mu \mathrm{m}$. c Two types of extratumoral local lymphovascular invasion observed in tumors. Invaded cells presented as tumor emboli composed of well-cohesive tumor cells (top panel, left), and more rarely seen invaded cells remained as scattered individual cells (top row, right). 468-shCDH1-B tumor emboli were smaller than the rest and composed of loosely adhered cells (middle row). Tumor cells were also observed within intratumoral blood vessels of 468-shCDH1-B tumors (bottom row). WT Wild type 
The majority of tumor emboli seen in vessels were E-cadherin-positive, indicating their epithelial phenotype. Although it is generally accepted that MET occurs to facilitate growth at the secondary site, our observations suggest that it may occur earlier in the bloodstream and further support the requirement of epithelial features, potentially through MET, during metastatic progression.

The presence of multinuclear tumor giant cells is indicative of the highly aggressive nature of the 468shCDH1-B group (Fig. 9b). These features stained positive for human vimentin, indicating their human origin.

\section{Trend for association of lung metastases with higher E-cadherin level}

Attempts to assess the lung metastasis efficiency of the different MDA-MB-468 cell populations via experimental metastasis were unsuccessful because tail vein injection in SCID mice did not result in any lung metastases in our hands. However, our experiments were compromised by the small number of lung metastases arising from the orthotopic primary xenografts across all groups (Table 4). The incidence of lung metastases, expressed as a percentage of mice in each group with lung metastases, appeared markedly lower in mice carrying 468shCDH1-B or 468-shCDH1-D xenografts than with the 468-SCR, suggesting that E-cadherin knockdown adversely affected the establishment of secondary colonies; however, this trend observed among the groups was not significant. This assumption was reinforced by the observation that the percentage of mice with lung metastases was slightly higher in the E-cadherin-overexpressing 468-CDH1 group than in the vector control (Table 4). Although the tumors grew at different rates, the mice were harvested as close to the same size as possible (Additional file 2: Figure S2b).

\section{Correlation of $\mathrm{CDH} 1$ protein expression with distant metastasis-free survival in individuals with breast cancer}

To determine whether E-cadherin expression predicted distant metastasis formation, an analysis of public breast cancer databases that had outcome data was performed [77, 78]. Patients' breast tumors were separated according to PAM50 intrinsic subtypes (basal, HER2-positive, luminal $\mathrm{A}$, luminal $\mathrm{B}$, or normal), and the mean centered $C D H 1$ expression was examined (Fig. 10a, $i$ ). In patients with tumors of the luminal B subtype, E-cadherin expression was expressed the highest $(p>0.001$ by oneway ANOVA for luminal B versus basal). Of the various tumor subtypes, a greater percentage of samples with distant metastases was observed when they were of the luminal B subtype, and subsequently this tumor type was more likely to present as metastasis within 15 years (Fig. 10a, ii and iii, respectively) $(p<0.0001)$. When these same data were plotted as the presence or absence of metastasis, $C D H 1$ expression was a determining factor (Fig. 10b, $i)(p=0.0037)$. This was consistent with analysis of The Cancer Genome Atlas breast cancer dataset [77] (Fig. 10b, ii) ( $p=0.0085)$, in which tumors were separated on the TNM staging scale of M0 being no distant metastasis and M1 indicating tumors that metastasized to distant organs (i.e., beyond the regional LNs).

\section{Discussion}

As previously reported [66], we have shown that the MDA-MB-468 human breast cancer cell line displays significant EMP in vivo, dynamically switching on a mesenchymal phenotype in the primary tumor either at the periphery or in response to HPX (EMT) but exhibiting a predominantly epithelial phenotype in the xenograft center and at the secondary sites in local LNs and the lung. Our in vivo study suggests that in this model, E-cadherin is a major phenotypic driver for metastatic colonization and is lost in EMT sites of the primary tumor, and this was supported by the poorer survival seen in grade III breast cancers expressing high levels of E-cadherin mRNA. The sustained and exaggerated EMT seen after E-cadherin suppression by shRNA in vivo, however, was not readily seen in vitro, suggesting that other factors in the tumor microenvironment are necessary for the full EMT program. Further to this, we have identified that E-cadherin promotes primary tumor growth but may also be important for the formation of lung metastases, thus disputing the previously held notion of E-cadherin as a tumor suppressor [79].

\section{Evidence challenging the tumor suppressor status of E-cadherin}

Evidence for E-cadherin's role as a tumor suppressor has accumulated, with downregulation of $\mathrm{CDH} 1$ being linked with epithelial tumor progression $[79,80]$, although its reexpression in tumors is reported to promote metastasis in later stages of tumor progression (reviewed in [14]). Indeed, inactivating mutations of the $\mathrm{CDH} 1$ gene in gastric and lobular breast cancers have defined Ecadherin as a tumor suppressor for these cancer types (reviewed in [81]). However, E-cadherin has an unexpected proneoplastic effect in ovarian cancer [82]. $\mathrm{CDH1}$ is upregulated in proliferating ovarian cancers, in which its suppression inhibits their proliferation [83, 84] and its proliferation-promoting effects in this context have been shown to occur via mitogen-activated protein kinase kinase/extracellular signal-regulated kinase pathway activation [85]. Perhaps consistent with this, breast cancers expressing higher levels of the epitheliumpromoting miR-200 family that represses the $C D H 1$-suppressing EMP drivers $Z E B 1$ and $Z E B 2$ have poorer outcomes; however, this appeared to be due to mechanisms 


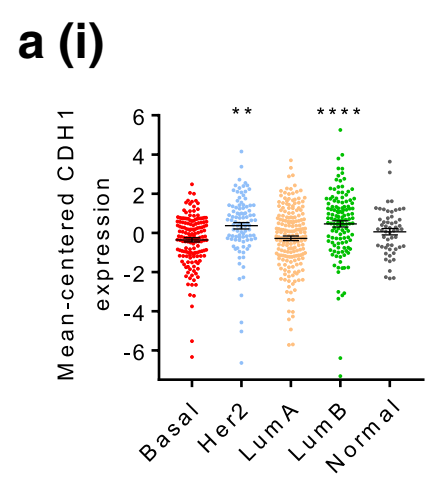

(ii)

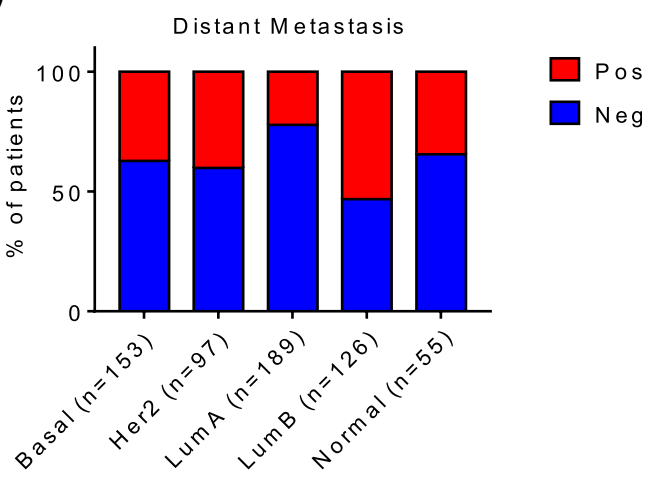

(iii)

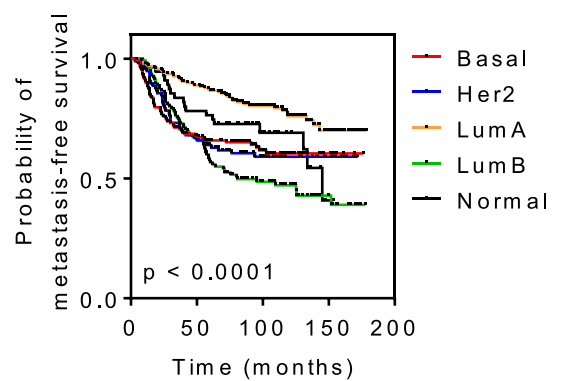

\section{b (i) $\quad$ Distant metastasis (ii)}

Yau et al., 2010
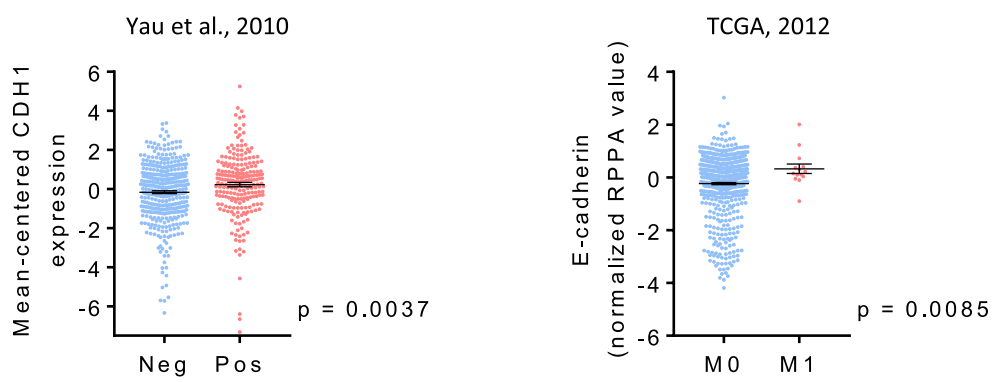

Fig. 10 E-cadherin expression correlates with poor clinical outcome for patients with breast cancer. a Analysis of clinical data of breast cancers separated according to PAM50 intrinsic subtype from a publicly available microarray study [78]. (i) CDH1 expression. ${ }^{* * *} p>0.001,{ }^{* *} p<0.01$, by one-way analysis of variance versus basal. (ii) Percentage of patients positive or negative for distant metastasis. (iii) Kaplan-Meier curve depicting the correlation between breast cancer subtype and distant metastasis-free survival. $p$ Value was determined by the log-rank (Mantel-Cox) statistical test. b Breast cancers that did or did not metastasize to distant sites were analyzed with respect to E-cadherin expression. (i) Data from Yau et al. [78], the same data source used for figures shown in (a) and (ii) [77]. $p$ Values were determined by Welch's $t$ test

additional to E-cadherin regulation [86]. Chu et al. [74], who also showed a reduced proliferative state after Ecadherin knockdown in the human breast cancer cell lines MARY-X and SUM149, found that higher levels of E-cadherin in basal breast cancers were associated with poorer outcome, consistent with our observations in luminal B tumors (Fig. 10). CDH1 and proliferative markers also correlated in a study of endometrial cancer [87] and have been associated with malignant and metastatic potential in bladder and prostate cancer cell lines [88]. We have also shown in the PMC42 human breast cancer model system that cellular proliferation was associated with an epithelial phenotype because the stable knockdown of ZEB1 in PMC42-ET cells resulted in $C D H 1$ reexpression along with an increased proliferative rate [38].

\section{E-cadherin-knockdown cells grew more slowly in vitro and in vivo}

In the present study, we have shown that E-cadherin greatly enabled the proliferation of MDA-MB-468 cells in vitro. These in vitro effects were recapitulated in the 
in vivo setting with dramatically reduced xenograft growth after E-cadherin suppression, with one minor exception: growth of the 468-shCDH1-D cells. These cells plated in vitro exhibited a noticeable reduction in proliferation rate only when plated sparsely (Fig. 4c, $i$ ). It is reasonable to assume that the growth environment of the tumors formed from these cells would not have been sparse; yet, as shown in Fig. 5a(ii), the 468-shCDH1-D tumors grew significantly slower than the control, indicating additional tumor microenvironmental factors at play.

Consistent with our overall findings that E-cadherin enabled cellular proliferation, a subline of the DU145 human prostate cancer cell line with strong E-cadherin expression formed xenograft tumors, whereas a subline of cells with weak E-cadherin expression did not form tumors at all [89]. Moreover, Celià-Terrassa et al. showed that the proliferative, malignant, and metastatic competence of both prostate (PC-3) and bladder (T24TSU) cell lines required E-cadherin expression, which also coincided with expression of pluripotency genes, and that manipulation of $\mathrm{CDH1}$ or pluripotency genes reciprocally affected each other [88]. A reduction in tumor growth has also been seen in MFP tumors of Ecadherin-knockdown SUM149 and MARY-X human breast cancer cells, in 4 T1 mouse mammary carcinoma cells, and in SUM149 cells engineered to overexpress $Z E B 1$, all of which demonstrated dramatic growth retardation compared with their respective controls [74].

HIF-1 $a$ and E-cadherin mechanistic effects on proliferation Gene expression analysis of the xenograft tumors from $\mathrm{Chu}$ et al. [74] revealed that E-cadherin knockdown caused a loss of HPX response genes, including HIF-1 $\alpha$, and that normal growth rate was restored in E-cadherinknockdown SUM149 xenografts by overexpressing HIF$1 \alpha$. In this particular study [74], it was deduced that the E-cadherin shRNA cell lines had a diminished ability to respond to hypoxic stress, and examination of the cells in vitro revealed a reduced capacity for glycolysis, which affected energy availability and growth potential. In the present study, we found that HIF- $1 \alpha$ expression was noticeably absent in 468-shCDH1-B tumors (which exhibited the best E-cadherin knockdown), whereas HIF-1 $\alpha$ was strongly expressed at the necrotic perimeter in tumors from other cell groups (Fig. 6a, right panel). Given that 468 -shCDH1-B tumors also grew the slowest in our studies, we considered the possibility that growth of the 468-shCDH1-B tumors was hampered by the inability of these cells to access energy by glycolysis and thus to survive in the hypoxic environment, as shown in Ecadherin knockdown in SUM149 cells [74]. We found, however, that the 468-shCDH1-B cells were not impaired in their ability to upregulate the HPX-inducible gene CAIX in hypoxic conditions simulated in vitro (Fig. 6c). It is probable that these tumors did not express HIF- $1 \alpha$ because they did not experience HPX, most likely attributable to their better-developed blood vasculature (Fig. 6a, left panel) afforded by slower tumor growth.

\section{Snail1 repressive effects on proliferation}

We demonstrated in our previous study that Snail1 and Snail2 were expressed in vimentin-positive zones within the MDA-MB-468 xenografts [66]. These act directly on the cell cycle to downregulate cellular proliferation [9092]. The 468-shCDH1-B tumors that were slowestgrowing also homogeneously expressed vimentin. These tumors also showed upregulated SNA1 (Fig. 8), which may have led to the observed slowed growth of these tumors (Fig. 5a, ii; Additional file 2: Figure S2a). Loss of Ecadherin at the cell membrane may have fueled SNA1 transcription via freed $\beta$-catenin acting in the nucleus [93]. ESR1 was downregulated in the 468-shCDH1-B tumors, a transcriptional target of SNA1 in EMT [76]. This provides support for the hypothesis that, in addition to upregulated SNA1 mRNA in the 468-shCDH1-B tumors, this resulted in upregulated Snail1 protein, which was transcriptionally active.

\section{E-cadherin loss does not always result in reduced cellular proliferation}

Although we have reviewed several lines of evidence to show that E-cadherin expression may provide a certain growth advantage in vivo, both in the onset of primary tumors and in their metastases, contradictory data suggest that loss of E-cadherin in some cell contexts does not reduce proliferation, and this is an important caveat. Indeed, proliferation is not always downregulated in EMP [94], and the EMP regulator and $C D H 1$ suppressor ZEB1 plays a pro-proliferative role in certain contexts $[95,96]$. The lack of EMP in lobular breast cancer, which is defined by loss of E-cadherin, suggests that lobular carcinoma cells have constraints that avoid any manifestation of EMP [67], and their lack of E-cadherin does not appear to compromise their ability to grow, perhaps due to some genomic override. In mammary systems, the relationship between EMP and stemness was accompanied by reduced proliferation in some studies $[9,43]$; however, EMP induced by ectopic expression of FOXC2 in EpRas cells did not affect either their proliferation rate in vitro or the growth kinetics of the resulting primary tumors in nude mice [29]. Ongoing stemness after MET has been suggested in studies examining PRRX1, a gene mediating EMT in migrating and invading cancer cells; downregulation of PRRX1 enables epithelial reversion, maintenance of stemness, and metastasis formation [50]. It is important to appreciate that the positive 
relationship between E-cadherin and proliferation described here, and as seen in several other systems, is not universal; however, the explanation for this remains unclear.

\section{E-cadherin-knockdown cells displayed a pronounced EMT within the tumor microenvironment}

The extent of in vivo vimentin expression across the various tumor groups strongly correlated with Ecadherin status (Fig. 7a). This was best observed in 468shCDH1-B tumors, which displayed the best E-cadherin knockdown (Fig. 3B), and also displayed the highest and most homogeneous expression of vimentin protein (Fig. 7a) and mRNA (Fig. 8). Upregulated VIM expression was not observed in the 468-shCDH1-B or 468shCDH1-D cells when plated in 2D or 3D (mRNA; Fig. 3c, $i i$, and Figs. 7c and Fig. 8, respectively), nor did the altered SNA1, ESR1, INHBA, and LAMC2 expression (from control) observed in tumors (Fig. 8) correlate in in vitro culture of the corresponding cells (Fig. 8). Induction of EMT by EGF did occur more easily (Fig. 3C), however. These results are similar to the findings of Chen et al., who showed that stable loss of E-cadherin in MCF10A cells did not drive EMT [97] and that loss of E-cadherin was not necessary or sufficient to induce EMT in cultured breast cells [98], as opposed to studies where E-cadherin loss did lead to EMT in vitro [71, 99]. It is likely that the in vivo EMT in the present study was influenced by murine stromal factors or biophysical influences. These stromal factors may also have induced an EMT at the tumor-stroma border in 468-WT tumors (Fig. 1a). One plausible host stromal candidate could include mast cell-derived interleukin-6, which we have previously implicated in a positive feedback cycle between tumor cells and host myofibroblasts in MDA-MB468 xenografts [100], although other soluble factors, microRNAs, and exosomes have been found to be released from tumor-activated stromal cells to promote EMT (reviewed in [101]). It is also possible that the duration of culture of these cells in the mouse (up to 154 weeks) led to different outcomes than seen in the relatively shorter time frames used in vitro.

\section{E-cadherin expression in metastases: importance of MET in secondary tumor formation}

WT MDA-MB-468 tumor cells that were found in the lung as micrometastases expressed E-cadherin, whereas no vimentin-positive cells were observed (Fig. 2b). Cells from the same primary tumor that invaded into the axillary LNs also demonstrated E-cadherin expression, with the E-cadherin signal in these cells even stronger than that of the primary tumor (Fig. 2c). E-cadherin expression may be advantageous for the formation of these lung metastases because we observed a trend toward a higher number of micrometastases in this organ in the mice carrying xenografts with forced E-cadherin (468$\mathrm{CDH} 1)$ than in their controls, as well as a reduced number when E-cadherin was knocked down despite the considerably longer tumor exposure time (Table 4). The sh-CDH1 xenografts grew slower, so the potential to seed metastases may have been reduced, and the lung metastases may have also grown slower. Kowalski et al. [102] reported results showing distant metastases expressing an E-cadherin signal equal to or stronger than that of the respective primary tumors from which they originated. They saw all metastatic tumors of invasive ductal carcinoma reexpressing E-cadherin, regardless of the E-cadherin status of the primary tumors. In other studies, Saha et al. [103] showed reexpression of Ecadherin in bone metastases that originated from Ecadherin-negative, poorly differentiated primary breast carcinoma, and Chao et al. [46] reported the reexpression of E-cadherin at distant metastases arising from Ecadherin-low or E-cadherin-negative primary tumors. They reported strong E-cadherin expression in more than $50 \%$ of liver, brain, and lung metastasis originating from infiltrating ductal carcinoma of the breast, as well as in lung metastases from E-cadherin-negative MDAMB-231 primary xenografts. They suggested that the reexpression of E-cadherin in metastases was influenced by the microenvironment of the metastatic site. To investigate their hypothesis, they demonstrated that the E-cadherin-negative MDA-MB-231 cells expressed Ecadherin when cocultured with hepatocytes. Similarly, activation of fibroblasts at the metastatic niche is mediated by $A X L$, expressed by mesenchymal circulating cancer cells homing to the niche, which has been shown to be necessary for metastatic colonization and MET [104]. Gao et al. showed that bone marrow-derived myeloid precursor cells produced versican that could neutralize transforming growth factor $\beta 1$ in the lung, promoting MET and metastatic competence in MDA-MB-231 cells [105]. MET may also occur in circulating tumor cells (CTCs) shed from the primary tumor, as has been shown in small cell lung cancer, where it has been postulated that the large CTC clusters that form may do so in response to the selection pressure of first-line chemotherapy [106]. Assessment of CTCs in a separate study of MDA-MB-468 xenografts showed significantly increased expression of both mesenchymal (SNAIL1, Notch homo$\log 1$, translocation-associated [Drosophila] [NOTCH1], SERPINE1, insulin-like growth factor 1 receptor, Rasrelated protein R-Ras, neurophilin 1, INHBA), and epithelial (B-lymphocyte antigen $C D 20, C D H 1$, bone morphogenetic protein 7 , claudin 3) markers (Tachtsidis, Li et al., unpublished data). VIM was increased, but not significantly. These findings, combined with those of the present study, support the importance of epithelial 
phenotype/MET tumor cell survival in the bloodstream and in the formation of secondary tumors and a central role for E-cadherin in this mechanism $[107,108]$.

\section{Features of aggressiveness in 468-shCDH1-B tumors}

Consistent with their more invasive status as established by the Transwell migration assays (Fig. 4a, ii), 468shCDH1-B displayed classical "high-grade" tumor aggressiveness features such as multinucleated giant cells (Fig. 9b) and an Indian file histology characteristic of lobular breast cancers, which are defined by a lack of Ecadherin. The presence of such morphologies in invasive breast carcinoma has been reported, although the origin of those cells has been a subject of controversy [109111]. Factor et al. suggested that giant cells are histiocytic descendants [109], whereas Kobayashi et al. proposed that they originated from the tumor cells through abnormal cell division [110]. Another study suggested that tumor giant cells are generated through the fusion of mononuclear stromal cells other than histiocytes [111]. Given that these cells expressed human vimentin, it appeared that these giant cells were of tumor origin. MDA-MB-468-shCDH1-B tumors grew more slowly than controls (Fig. 5a, ii), and thus, combined with the expression of these aggressive phenotypic features, these findings challenge the generally accepted view of "the higher the grade, the more aggressive and fast-growing the cancer."

\section{E-cadherin expression determines distant metastasis formation}

In our study, we have shown that the E-cadherinknockdown cell lines displayed a trend toward fewer lung metastases (Table 4), indicating that E-cadherin is important for the formation of these secondary tumors. A previous study looking at E-cadherin expression in tumors of all types and patient survival found that Ecadherin did not have predictive value [86], whereas another study showed that E-cadherin expression (in basal tumors specifically) was associated with a poor prognosis [74]. The clinical data shown in Fig. 10 are consistent with this latter finding and demonstrate that E-cadherin expression is a feature of tumors that metastasize to distant sites, concordant with the results of another study in which it was shown that luminal B breast cancers are associated with a poorer prognosis [112]. In this particular study, they showed that this breast tumor subtype was also more proliferative, displaying a higher Ki-67 score. This is consistent with our finding that E-cadherin promotes a proliferative phenotype, as shown in Figs. 4 and 5. Taken together, E-cadherin expression in breast cancer has significant implications for patient outcome.

\section{Conclusions}

We have shown that E-cadherin expression sustains proliferation in MDA-MB-468 breast cancer cells in culture and within the growing tumor at both orthotopic and metastatic sites in the SCID mouse. We have also demonstrated that EMP is influenced by the tumor microenvironment and is stimulated by HPX and stromal interactions. We have shown that predominantly epithelial features are seen in tumor-associated LVI, proximal vascular emboli, and local LNs, as well as in lung metastases, and these are consistent with our independent studies of CTCs in this model. Our review of the clinical data with respect to E-cadherin expression in breast tumors support that E-cadherin expression positively predicts the formation of metastases. These findings indicate the requirement of a reappraisal of the precise role of E-cadherin in predicting primary tumor progression and metastatic risk.

\section{Additional files}

Additional file 1: Figure S1. a Further examples of MDA-MB-468 cell xenograft images shown in Fig. 1b. (PDF 203 kb)

Additional file 2: Figure S2. a Comparison of individual tumor growth plots for 468-shCDH1-B and 468-shCDH1-D tumors to day of tumor harvest. $\mathbf{b}$ Tumor volumes at time mice were killed did not differ greatly. (PDF $106 \mathrm{~kb}$ )

Additional file 3: Figure S3. Ki-67 immunostaining of the various Ecadherin-modified murine tumors, showing no difference in number of positive nuclei.tr (PDF $283 \mathrm{~kb}$ )

\begin{abstract}
Abbreviations
AEC: Animal ethics committee; ANOVA: Analysis of variance; BSA: Bovine serum albumin; $C A I X$ : Carbonic anhydrase 9; $C D H 1$ : E-cadherin gene; CTC: Circulating tumor cell; DAB: 3,3'-Diaminobenzidine; DAPI: 4',6-diamidino2-phenylindole; DPX: Dibutylphthalate polystyrene xylene; EGF: Epidermal growth factor; EMP: Epithelial-mesenchymal plasticity; EMT: Epithelial-tomesenchymal transition; ER: Estrogen receptor; ESR1: Estrogen receptor alpha; FOXC2: Forkhead box protein C2; G418: Geneticin; GFP: Green fluorescent protein; H\&E: Hematoxylin and eosin; HIF: Hypoxia-inducible factor; HPX: Hypoxia; IgG: Immunoglobulin G; IHC: Immunohistochemistry; INHBA: Inhibin, beta A; LN: Lymph node; LVI: Lymphovascular invasion; MET: Mesenchymal-to-epithelial transition; MFP: Mammary fat pad; miR: MicroRNA; mRNA: Messenger RNA; NOTCH1: Notch homolog 1, translocation-associated (Drosophila); OD: Optical density; qPCR: Quantitative polymerase chain reaction; SCID: Severe combined immunodeficiency; SCR: Scrambled; SERPINE1: Serpin family E member 1; shRNA: Short hairpin RNA; SNAI1: Snail family transcriptional repressor 1; SNAI2: Snail family transcriptional repressor 2; SRB: Sulforhodamine B; TCA: Trichloroacetic acid; TCGA: The Cancer Genome Atlas; UTR: Untranslated region; WT: Wild type; ZEB1: Zinc finger E-box-binding homeobox 1; ZEB2: Zinc finger E-box-binding homeobox 2; $\Delta \mathrm{CT}$ : Cycle threshold change
\end{abstract}

\section{Acknowledgements}

We thank Associate Professor Alex Dobrovic, who helped analyze the pilot MDA-MB-468 mouse experiments in collaboration with MW, TB, and EWT.

\section{Funding}

This work and EWT were supported in part by the EMPathy Breast Cancer Network (CG-10-04), a National Collaborative Research Program of the National Breast Cancer Foundation (Australia). This study benefited from support provided by the Victorian Government's Operational Infrastructure Support Program to St. Vincent's Institute. 


\section{Availability of data and materials}

All data generated or analyzed during this study are included in this published article and its supplementary information files.

\section{Authors' contributions}

NPADG, under the supervision of EWT and $\mathrm{HJH}$, carried out all experiments reported in this article. $\mathrm{HJH}$ participated in the study design and coordination and composed the manuscript. BGH undertook datamining, analysis and interpretation of clinical databases for E-cadherin depicted in figure 10. AT provided the E-cadherin expression constructs, provided advice on experimental design, helped interpret the data, and helped compose the manuscript. TT undertook the 3D studies of shCDH1 cells and helped compose the manuscript. TB participated in the design of the study, provided guidance in the in vivo experimentation of E-cadherin-manipulated MDA-MB468 cells, performed the statistical analyses, and helped compose the manuscript. PH provided assistance in the interpretation of histological morphology and immunohistochemical analyses and helped interpret the data. MW provided guidance in the in vivo experimentation of E-cadherinmanipulated MDA-MB-468 cells. CG assisted in the interpretation of the data and helped compose the manuscript. EWT conceived of the study, participated directly in its design and coordination, helped interpret the data, and helped compose the manuscript. All authors read and approved the final manuscript.

\section{Ethics approval and consent to participate}

All of the experimental procedures pertaining to inoculation of SCID mice with E-cadherin-modified cell lines were performed according to the guidelines stipulated by the animal ethics committee (AEC) at St. Vincent's Hospital, Melbourne (AEC protocol number 008/08)

\section{Consent for publication}

Not applicable.

\section{Competing interests}

The authors declare that they have no competing interests.

\section{Publisher's note}

Springer Nature remains neutral with regard to jurisdictional claims in published maps and institutional affiliations.

\section{Author details}

'Invasion and Metastasis Unit, St. Vincent's Institute, Melbourne, VIC, Australia. ${ }^{2}$ Institute of Health and Biomedical Innovation, Queensland University of Technology, Brisbane, QLD, Australia. ${ }^{3}$ School of Biomedical Sciences, Queensland University of Technology, Brisbane, QLD, Australia. ${ }^{4}$ Translational Research Institute, Woolloongabba, QLD, Australia. ${ }^{5}$ Department of Surgery, University of Melbourne, St. Vincent's Hospital, Melbourne, VIC, Australia. ${ }^{6}$ Department of Pathology, University of Melbourne, Melbourne, VIC, Australia. ${ }^{7}$ Interdisciplinary Cluster for Applied Genoproteomics (GIGA)-Cancer, Laboratory of Tumor and Development Biology, University of Liège, Liège, Belgium. ${ }^{8}$ Institute of Health and Biomedical Innovation, Queensland University of Technology, Brisbane, Australia. ${ }^{9}$ Australian Prostate Cancer Research Centre-Queensland, Brisbane, Australia.

Received: 8 May 2017 Accepted: 7 July 2017

Published online: 27 July 2017

\section{References}

1. Australian Institute of Health and Welfare (AIHW). Australian cancer incidence and mortality (ACIM) books: breast cancer. Canberra: AlHW; 2016. http://www.aihw.gov.au/acim-books/. Accessed 12 Jul 2017.

2. Mettlin C. Global breast cancer mortality statistics. CA Cancer I Clin. 1999;49: $138-44$

3. Breast cancer statistics. J Natl Cancer Inst. 2000;92:445.

4. Gunasinghe NP, Wells A, Thompson EW, Hugo HJ. Mesenchymal-epithelial transition (MET) as a mechanism for metastatic colonisation in breast cancer. Cancer Metastasis Rev. 2012;31:469-78.

5. Jie XX, Zhang $X Y, X u C J$. Epithelial-to-mesenchymal transition, circulating tumor cells and cancer metastasis: mechanisms and clinical applications. Oncotarget. 2017. doi:10.18632/oncotarget.18277.
6. Guo W, Keckesova Z, Donaher JL, Shibue T, Tischler V, Reinhardt F, et al. Slug and Sox9 cooperatively determine the mammary stem cell state. Cell. 2012;148:1015-28

7. Howlett AR, Bissell MJ. The influence of tissue microenvironment (stroma and extracellular matrix) on the development and function of mammary epithelium. Epithelial Cell Biol. 1993;2:79-89.

8. Lee K, Gjorevski N, Boghaert E, Radisky DC, Nelson CM. Snail1, Snail2, and E47 promote mammary epithelial branching morphogenesis. EMBO J. 2011; 30:2662-74.

9. Nassour M, Idoux-Gillet Y, Selmi A, Come C, Faraldo ML, Deugnier MA, et al. Slug controls stem/progenitor cell growth dynamics during mammary gland morphogenesis. PLoS One. 2012;7:e53498.

10. Wang D, Cai C, Dong X, Yu QC, Zhang XO, Yang L, et al. Identification of multipotent mammary stem cells by protein $C$ receptor expression. Nature. 2015:517:81-4.

11. Ye X, Tam WL, Shibue T, Kaygusuz Y, Reinhardt F, Ng Eaton E, et al. Distinct EMT programs control normal mammary stem cells and tumour-initiating cells. Nature. 2015;525:256-60.

12. Blick T, Hugo H, Widodo E, Waltham M, Pinto C, Mani SA, et al. Epithelial mesenchymal transition traits in human breast cancer cell lines parallel the $\mathrm{CD} 44^{\text {hi/ }} \mathrm{CD} 24^{\mathrm{lo} / \text { s }}$ stem cell phenotype in human breast cancer. J Mammary Gland Biol Neoplasia. 2010;15:235-52.

13. Pinto CA, Widodo E, Waltham M, Thompson EW. Breast cancer stem cells and epithelial mesenchymal plasticity - implications for chemoresistance. Cancer Lett. 2013;341:56-62.

14. Hugo H, Ackland ML, Blick T, Lawrence MG, Clements JA, Williams ED, et al. Epithelial-mesenchymal and mesenchymal-epithelial transitions in carcinoma progression. J Cell Physiol. 2007;213:374-83.

15. Savagner P. Epithelial-mesenchymal transitions: from cell plasticity to concept elasticity. Curr Top Dev Biol. 2015;112:273-300.

16. Thiery JP. Epithelial-mesenchymal transitions in tumour progression. Nat Rev Cancer. 2002:2:442-54.

17. Tse JC, Kalluri R. Mechanisms of metastasis: epithelial-to-mesenchymal transition and contribution of tumor microenvironment. J Cell Biochem. 2007;101:816-29.

18. van Denderen BJ, Thompson EW. Cancer: the to and fro of tumour spread. Nature. 2013;493:487-8.

19. Gumbiner BM. Cell adhesion: the molecular basis of tissue architecture and morphogenesis. Cell. 1996;84:345-57.

20. Gumbiner BM. Regulation of cadherin adhesive activity. J Cell Biol. 2000;148: 399-404.

21. Larue L, Antos C, Butz S, Huber O, Delmas V, Dominis M, et al. A role for cadherins in tissue formation. Development. 1996;122:3185-94.

22. Larue L, Ohsugi M, Hirchenhain J, Kemler R. E-cadherin null mutant embryos fail to form a trophectoderm epithelium. Proc Natl Acad Sci U S A. 1994;91:8263-7.

23. Birchmeier W, Behrens J. Cadherin expression in carcinomas: role in the formation of cell junctions and the prevention of invasiveness. Biochim Biophys Acta. 1994;1198:11-26.

24. Cano A, Perez-Moreno MA, Rodrigo I, Locascio A, Blanco MJ, del Barrio MG, et al. The transcription factor snail controls epithelial-mesenchymal transitions by repressing E-cadherin expression. Nat Cell Biol. 2000;2:76-83.

25. Batlle E, Sancho E, Francí C, Domínguez D, Monfar M, Baulida J, et al. The transcription factor Snail is a repressor of E-cadherin gene expression in epithelial tumour cells. Nat Cell Biol. 2000;2:84-9.

26. Bolos V, Peinado H, Perez-Moreno MA, Fraga MF, Esteller M, Cano A. The transcription factor Slug represses E-cadherin expression and induces epithelial to mesenchymal transitions: a comparison with Snail and E47 repressors. J Cell Sci. 2003;116:499-511.

27. Comijn J, Berx G, Vermassen P, Verschueren $K$, van Grunsven L, Bruyneel E, et al. The two-handed $\mathrm{E}$ box binding zinc finger protein SIP1 downregulates E-cadherin and induces invasion. Mol Cell. 2001;7:1267-78.

28. Eger A, Aigner K, Sonderegger S, Dampier B, Oehler S, Schreiber M, et al. DeltaEF1 is a transcriptional repressor of E-cadherin and regulates epithelial plasticity in breast cancer cells. Oncogene. 2005;24:2375-85.

29. Mani SA, Yang J, Brooks M, Schwaninger G, Zhou A, Miura N, et al. Mesenchyme Forkhead 1 (FOXC2) plays a key role in metastasis and is associated with aggressive basal-like breast cancers. Proc Natl Acad Sci U S A. 2007:104:10069-74.

30. Hartwell KA, Muir B, Reinhardt F, Carpenter AE, Sgroi DC, Weinberg RA. The Spemann organizer gene, Goosecoid, promotes tumor metastasis. Proc Natl Acad Sci U S A. 2006;103:18969-74. 
31. Bloch-Zupan A, Hunter N, Manthey A, Gibbins J. R-twist gene expression during rat palatogenesis. Int J Dev Biol. 2001;45:397-404.

32. Rosivatz E, Becker I, Specht K, Fricke E, Luber B, Busch R, et al. Differential expression of the epithelial-mesenchymal transition regulators Snail, SIP1, and Twist in gastric cancer. Am J Pathol. 2002;161:1881-91.

33. Moreno-Bueno G, Portillo F, Cano A. Transcriptional regulation of cell polarity in EMT and cancer. Oncogene. 2008;27:6958-69.

34. Thiery JP, Acloque H, Huang RY, Nieto MA. Epithelial-mesenchymal transitions in development and disease. Cell. 2009;139:871-90.

35. Thompson EW, Haviv I. The social aspects of EMT-MET plasticity. Nat Med. 2011;17:1048-9.

36. Behrens J, Weidner KM, Frixen UH, Schipper JH, Sachs M, Arakaki N, et al. The role of E-cadherin and scatter factor in tumor invasion and cell motility. EXS. 1991;59:109-26.

37. Berx G, Van Roy F. The E-cadherin/catenin complex: an important gatekeeper in breast cancer tumorigenesis and malignant progression. Breast Cancer Res. 2001;3:289-93.

38. Hugo HJ, Pereira L, Suryadinata R, Drabsch Y, Gonda TJ, Gunasinghe NP, et al. Direct repression of MYB by ZEB1 suppresses proliferation and epithelial gene expression during epithelial-to-mesenchymal transition of breast cancer cells. Breast Cancer Res. 2013;15:R113.

39. Rubio CA. Further studies on the arrest of cell proliferation in tumor cells at the invading front of colonic adenocarcinoma. J Gastroenterol Hepatol. 2007;22:1877-81.

40. Chen S, Chen JZ, Zhang JQ, Chen HX, Yan ML, Huang L, et al. Hypoxia induces Twist-activated epithelial-mesenchymal transition and proliferation of pancreatic cancer cells in vitro and in nude mice. Cancer Lett. 2016;383: 73-84.

41. Liu LZ, He YZ, Dong PP, Ma LJ, Wang ZC, Liu XY, et al. Protein tyrosine phosphatase PTP4A1 promotes proliferation and epithelial-mesenchymal transition in intrahepatic cholangiocarcinoma via the PI3K/AKT pathway. Oncotarget. 2016;7:75210-20.

42. Brabletz T, Jung A, Reu S, Porzner M, Hlubek F, Kunz-Schughart LA, et al. Variable $\beta$-catenin expression in colorectal cancers indicates tumor progression driven by the tumor environment. Proc Natl Acad Sci U S A. 2001;98:10356-61.

43. Liu S, Cong Y, Wang D, Sun Y, Deng L, Liu Y, et al. Breast cancer stem cells transition between epithelial and mesenchymal states reflective of their normal counterparts. Stem Cell Rep. 2014;2:78-91.

44. Fang S, Yu L, Mei H, Yang J, Gao T, Cheng A, et al. Cisplatin promotes mesenchymal-like characteristics in osteosarcoma through Snail. Oncol Lett. 2016;12:5007-14

45. Woolf AS, Kolatsi-Joannou M, Hardman P, Andermarcher E, Moorby C, Fine LG, et al. Roles of hepatocyte growth factor/scatter factor and the met receptor in the early development of the metanephros. J Cell Biol. 1995;128:171-84.

46. Chao YL, Shepard CR, Wells A. Breast carcinoma cells re-express E-cadherin during mesenchymal to epithelial reverting transition. Mol Cancer. 2010;9: 179 .

47. Chaffer CL, Brennan JP, Slavin JL, Blick T, Thompson EW, Williams ED. Mesenchymal-to-epithelial transition facilitates bladder cancer metastasis: role of fibroblast growth factor receptor-2. Cancer Res. 2006;66:11271-8.

48. Chaffer $\mathrm{CL}$, Thompson EW, Williams ED. Mesenchymal to epithelial transition in development and disease. Cells Tissues Organs. 2007;185:7-19.

49. Tsai JH, Donaher JL, Murphy DA, Chau S, Yang J. Spatiotemporal regulation of epithelial-mesenchymal transition is essential for squamous cell carcinoma metastasis. Cancer Cell. 2012;22:725-36.

50. Ocana OH, Corcoles R, Fabra A, Moreno-Bueno G, Acloque H, Vega S, et al. Metastatic colonization requires the repression of the epithelialmesenchymal transition inducer Prrx1. Cancer Cell. 2012;22:709-24.

51. Nakamura M, Onoda N, Noda S, Kashiwagi S, Aomatsu N, Kurata K, et al. Ecadherin expression and cell proliferation in the primary tumor and metastatic lymph nodes of papillary thyroid microcarcinoma. Mol Clin Oncol. 2014;2:226-32.

52. Chao $Y$, Wu Q, Acquafondata M, Dhir R, Wells A. Partial mesenchymal to epithelial reverting transition in breast and prostate cancer metastases. Cancer Microenviron. 2012;5:19-28.

53. Ruscetti M, Quach B, Dadashian EL, Mulholland DJ, Wu H. Tracking and functional characterization of epithelial-mesenchymal transition and mesenchymal tumor cells during prostate cancer metastasis. Cancer Res. 2015;75:2749-59.

54. Wells A, Yates C, Shepard CR. E-cadherin as an indicator of mesenchymal to epithelial reverting transitions during the metastatic seeding of disseminated carcinomas. Clin Exp Metastasis. 2008;25:621-8.
55. Tran HD, Luitel K, Kim M, Zhang K, Longmore GD, Tran DD. Transient SNAIL1 expression is necessary for metastatic competence in breast cancer. Cancer Res. 2014;74:6330-40.

56. Lu R, Serrero G. Inhibition of PC cell-derived growth factor (PCDGF, epithelin/granulin precursor) expression by antisense PCDGF CDNA transfection inhibits tumorigenicity of the human breast carcinoma cell line MDA-MB-468. Proc Natl Acad Sci U S A. 2000;97:3993-8.

57. Akcakanat A, Zhang L, Tsavachidis S, Meric-Bernstam F. The rapamycinregulated gene expression signature determines prognosis for breast cancer. Mol Cancer. 2009;8:75.

58. Xu L, Yin S, Banerjee S, Sarkar F, Reddy KB. Enhanced anticancer effect of the combination of cisplatin and TRAIL in triple-negative breast tumor cells. Mol Cancer Ther. 2011;10:550-7.

59. Price JE, Zhang RD. Studies of human breast cancer metastasis using nude mice. Cancer Metastasis Rev. 1990:8:285-97.

60. Sheridan C, Kishimoto H, Fuchs RK, Mehrotra S, Bhat-Nakshatri P, Turner CH, et al. CD44 $/$ CD24 $4^{-}$breast cancer cells exhibit enhanced invasive properties: an early step necessary for metastasis. Breast Cancer Res. 2006;8:R59.

61. Vantyghem SA, Allan AL, Postenka CO, Al-Katib W, Keeney M, Tuck AB, et al. A new model for lymphatic metastasis: development of a variant of the MDA-MB-468 human breast cancer cell line that aggressively metastasizes to lymph nodes. Clin Exp Metastasis. 2005;22:351-61.

62. Thompson EW, Paik S, Brunner N, Sommers CL, Zugmaier G, Clarke R, et al. Association of increased basement membrane invasiveness with absence of estrogen receptor and expression of vimentin in human breast cancer cell lines. J Cell Physiol. 1992;150:534-44.

63. Skehan P, Storeng R, Scudiero D, Monks A, McMahon J, Vistica D, et al. New colorimetric cytotoxicity assay for anticancer-drug screening. J Natl Cancer Inst. 1990;82:1107-12.

64. Gottardi CJ, Wong E, Gumbiner BM. E-cadherin suppresses cellular transformation by inhibiting $\beta$-catenin signaling in an adhesionindependent manner. J Cell Biol. 2001;153:1049-60.

65. Price JT, Thompson EW. Models for studying cellular invasion of basement membranes. Methods Mol Biol. 1999;129:231-49.

66. Bonnomet A, Syne L, Brysse A, Feyereisen E, Thompson EW, Noel A, et al. A dynamic in vivo model of epithelial-to-mesenchymal transitions in circulating tumor cells and metastases of breast cancer. Oncogene. 2012;31: 3741-53.

67. MCCart Reed AE, Kutasovic JR, Vargas AC, Jayanthan J, Al-Murrani A, Reid LE, et al. An epithelial to mesenchymal transition programme does not usually drive the phenotype of invasive lobular carcinomas. J Pathol. 2016;238:489-94.

68. Jo M, Lester RD, Montel V, Eastman B, Takimoto S, Gonias SL. Reversibility of epithelial-mesenchymal transition (EMT) induced in breast cancer cells by activation of urokinase receptor-dependent cell signaling. J Biol Chem. 2009;284:22825-33.

69. Lundgren K, Nordenskjöld B, Landberg G. Hypoxia, Snail and incomplete epithelial-mesenchymal transition in breast cancer. Br J Cancer. 2009;101: 1769-81.

70. Cursons J, Leuchowius KJ, Waltham M, Tomaskovic-Crook E, Foroutan M, Bracken $C P$, et al. Stimulus-dependent differences in signalling regulate epithelial-mesenchymal plasticity and change the effects of drugs in breast cancer cell lines. Cell Commun Signal. 2015;13:26.

71. Onder TT, Gupta PB, Mani SA, Yang J, Lander ES, Weinberg RA. Loss of Ecadherin promotes metastasis via multiple downstream transcriptional pathways. Cancer Res. 2008;68:3645-54.

72. Zuo JH, Zhu W, Li MY, Li XH, Yi H, Zeng GQ, et al. Activation of EGFR promotes squamous carcinoma SCC10A cell migration and invasion via inducing EMT-like phenotype change and MMP-9-mediated degradation of E-cadherin. J Cell Biochem. 2011;112:2508-17.

73. Vleminckx K, Vakaet Jr L, Mareel M, Fiers W, van Roy F. Genetic manipulation of E-cadherin expression by epithelial tumor cells reveals an invasion suppressor role. Cell. 1991;66:107-19.

74. Chu K, Boley KM, Moraes R, Barsky SH, Robertson FM. The paradox of Ecadherin: role in response to hypoxia in the tumor microenvironment and regulation of energy metabolism. Oncotarget. 2013;4:446-62.

75. Ribeiro AS, Paredes J. P-cadherin linking breast cancer stem cells and invasion: a promising marker to identify an "intermediate/metastable" EMT state. Front Oncol. 2015:4:371.

76. Dhasarathy A, Kajita M, Wade PA. The transcription factor snail mediates epithelial to mesenchymal transitions by repression of estrogen receptor-a. Mol Endocrinol. 2007;21:2907-18. 
77. The Cancer Genome Atlas Network. Comprehensive molecular portraits of human breast tumours. Nature. 2012;490:61-70.

78. Yau C, Esserman L, Moore DH, Waldman F, Sninsky J, Benz CC. A multigene predictor of metastatic outcome in early stage hormone receptor-negative and triple-negative breast cancer. Breast Cancer Res. 2010;12:R85.

79. Perl AK, Wilgenbus P, Dahl U, Semb H, Christofori G. A causal role for E-cadherin in the transition from adenoma to carcinoma. Nature. 1998;392:190-3.

80. Herzig M, Savarese F, Novatchkova M, Semb H, Christofori G. Tumor progression induced by the loss of E-cadherin independent of $\beta$-catenin/ Tcf-mediated Wnt signaling. Oncogene. 2007;26:2290-8.

81. Berx G, Becker KF, Höfler H, van Roy F. Mutations of the human E-cadherin (CDH1) gene. Hum Mutat. 1998;12:226-37.

82. Auersperg N, Pan J, Grove BD, Peterson T, Fisher J, Maines-Bandiera S, et al. E-cadherin induces mesenchymal-to-epithelial transition in human ovarian surface epithelium. Proc Natl Acad Sci U S A. 1999;96:6249-54.

83. Sundfeldt K. Cell-cell adhesion in the normal ovary and ovarian tumors of epithelial origin; an exception to the rule. Mol Cell Endocrinol. 2003;202:89-96.

84. Reddy P, Liu L, Ren C, Lindgren P, Boman K, Shen Y, et al. Formation of Ecadherin-mediated cell-cell adhesion activates AKT and mitogen activated protein kinase via phosphatidylinositol 3 kinase and ligand-independent activation of epidermal growth factor receptor in ovarian cancer cells. Mol Endocrinol. 2005;19:2564-78.

85. Dong LL, Liu L, Ma CH, Li JS, Du C, Xu S, et al. E-cadherin promotes proliferation of human ovarian cancer cells in vitro via activating MEK/ERK pathway. Acta Pharmacol Sin. 2012;33:817-22.

86. Korpal M, Ell BJ, Buffa FM, Ibrahim T, Blanco MA, Celia-Terrassa T, et al. Direct targeting of Sec23a by miR-200s influences cancer cell secretome and promotes metastatic colonization. Nat Med. 2011;17:1101-8.

87. González-Rodilla I, Aller L, Llorca J, Muñoz AB, Verna V, Estévez J, et al. The E-cadherin expression vs. tumor cell proliferation paradox in endometrial cancer. Anticancer Res. 2013;33:5091-5.

88. Celià-Terrassa T, Meca-Cortés O, Mateo F. Martínez de Paz AM, Rubio N, Arnal-Estapé A, et al. Epithelial-mesenchymal transition can suppress major attributes of human epithelial tumor-initiating cells. J Clin Invest. 2012;122: 1849-68.

89. Putzke AP, Ventura AP, Bailey AM, Akture C, Opoku-Ansah J, Celiktas M, et al. Metastatic progression of prostate cancer and E-cadherin regulation by Zeb1 and Src family kinases. Am J Pathol. 2011;179:400-10.

90. Vega S, Morales AV, Ocana OH, Valdes F, Fabregat I, Nieto MA. Snail blocks the cell cycle and confers resistance to cell death. Genes Dev. 2004;18: $1131-43$.

91. Ding GX, Liu J, Feng CC, Jiang HW, Xu JF, Ding Q. Slug regulates cyclin D1 expression by ubiquitin-proteasome pathway in prostate cancer cells. Panminerva Med. 2012;54:219-23.

92. Wang WL, Huang HC, Kao SH, Hsu YC, Wang YT, Li KC, et al. Slug is temporally regulated by cyclin $\mathrm{E}$ in cell cycle and controls genome stability. Oncogene. 2015;34:1116-25.

93. Medici D, Hay ED, Olsen BR. Snail and Slug promote epithelial-mesenchymal transition through $\beta$-catenin-T-cell factor-4-dependent expression of transforming growth factor- $\beta 3$. Mol Biol Cell. 2008;19:4875-87.

94. Kim MS, Lee WS, Jeong J, Kim SJ, Jin W. Induction of metastatic potential by TrkB via activation of IL6/JAK2/STAT3 and PI3K/AKT signaling in breast cancer. Oncotarget. 2015;6:40158-71.

95. Fontemaggi G, Gurtner A, Strano S, Higashi Y, Sacchi A, Piaggio G, et al. The transcriptional repressor ZEB regulates $p 73$ expression at the crossroad between proliferation and differentiation. Mol Cell Biol. 2001;21:8461-70.

96. Hu F, Wang C, Du J, Sun W, Yan J, Mi D, et al. DeltaEF1 promotes breast cancer cell proliferation through down-regulating p21 expression. Biochim Biophys Acta. 1802;2010:301-12.

97. Chen A, Beetham H, Black MA, Priya R, Telford BJ, Guest J, et al. E-cadherin loss alters cytoskeletal organization and adhesion in non-malignant breast cells but is insufficient to induce an epithelial-mesenchymal transition. BMC Cancer. 2014;14:552.

98. Hollestelle A, Peeters JK, Smid M, Timmermans M, Verhoog LC, Westenend $P J$, et al. Loss of E-cadherin is not a necessity for epithelial to mesenchymal transition in human breast cancer. Breast Cancer Res Treat. 2013;138:47-57.

99. Bae GY, Choi SJ, Lee JS, Jo J, Lee J, Kim J, et al. Loss of E-cadherin activates EGFR-MEK/ERK signaling, which promotes invasion via the ZEB1/MMP2 axis in non-small cell lung cancer. Oncotarget. 2013;4:2512-22.

100. Hugo HJ, Lebret S, Tomaskovic-Crook E, Ahmed N, Blick T, Newgreen DF, et al. Contribution of fibroblast and mast cell (afferent) and tumor (efferent) IL-
6 effects within the tumor microenvironment. Cancer Microenviron. 2012;5: 83-93.

101. Bussard KM, Mutkus L, Stumpf K, Gomez-Manzano C, Marini FC. Tumorassociated stromal cells as key contributors to the tumor microenvironment. Breast Cancer Res. 2016;18:84.

102. Kowalski PJ, Rubin MA, Kleer CG. E-cadherin expression in primary carcinomas of the breast and its distant metastases. Breast Cancer Res. 2003; 5:R217-22.

103. Saha B, Chaiwun B, Imam SS, Tsao-Wei DD, Groshen S, Naritoku WY, et al. Overexpression of E-cadherin protein in metastatic breast cancer cells in bone. Anticancer Res. 2007:27:3903-8.

104. Del Pozo MY, Park D, Ramachandran A, Ombrato L, Calvo F, Chakravarty P, et al. Mesenchymal cancer cell-stroma crosstalk promotes niche activation, epithelial reversion, and metastatic colonization. Cell Rep. 2015;13:2456-69.

105. Gao D, Joshi N, Choi H, Ryu S, Hahn M, Catena R, et al. Myeloid progenitor cells in the premetastatic lung promote metastases by inducing mesenchymal to epithelial transition. Cancer Res. 2012;72:1384-94.

106. Hamilton G, Hochmair M, Rath B, Klameth L, Zeillinger R. Small cell lung cancer: circulating tumor cells of extended stage patients express a mesenchymal-epithelial transition phenotype. Cell Adh Migr. 2016;10:360-7.

107. Fischer KR, Durrans A, Lee S, Sheng J, Li F, Wong ST, et al. Epithelial-tomesenchymal transition is not required for lung metastasis but contributes to chemoresistance. Nature. 2015;527:472-6.

108. Zheng X, Carstens JL, Kim J, Scheible M, Kaye J, Sugimoto H, et al. Epithelialto-mesenchymal transition is dispensable for metastasis but induces chemoresistance in pancreatic cancer. Nature. 2015;527:525-30.

109. Factor SM, Biempica L, Ratner I, Ahuja KK, Biempica S. Carcinoma of the breast with multinucleated reactive stromal giant cells: a light and electron microscopic study of two cases. Virchows Arch A Pathol Anat Histol. 1977; $374: 1-12$.

110. Kobayashi S, Tobioka N, Samoto T, Kobayashi M, Iwase H, Masaoka A, et al. Breast cancer with osteoclast-like multinucleated giant cells. Acta Pathol Jpn. 1984;34:1475-84.

111. Nielsen BB, Kiaer HW. Carcinoma of the breast with stromal multinucleated giant cells. Histopathology. 1985;9:183-93.

112. Cheang MC, Chia SK, Voduc D, Gao D, Leung S, Snider J, et al. Ki67 index, HER2 status, and prognosis of patients with luminal B breast cancer. J Natl Cancer Inst. 2009;101:736-50.

\section{Submit your next manuscript to BioMed Central and we will help you at every step:}

- We accept pre-submission inquiries

- Our selector tool helps you to find the most relevant journal

- We provide round the clock customer support

- Convenient online submission

- Thorough peer review

- Inclusion in PubMed and all major indexing services

- Maximum visibility for your research

Submit your manuscript at www.biomedcentral.com/submit
) Biomed Central 